\title{
$\begin{array}{ll}\text { Research Square } & \text { Preprints are preliminary reports that have not undergone peer review. } \\ \text { They should not be considered conclusive, used to inform clinical practice, }\end{array}$ or referenced by the media as validated information. \\ Cellulose Nanofiber, Lignin, and Hemicellulose as Value-Added Products From Recycled Old Corrugated Box (OCB)
}

\section{Sumit S Lal}

ICT: Institute of Chemical Technology https://orcid.org/0000-0002-6374-765X

Ajit P Patil

ICT: Institute of Chemical Technology

Ganesh A Phalak

ICT: Institute of Chemical Technology

Shashank Mhaske ( $\nabla$ stmhaske@gmail.com )

Institute of Chemical Technology

\section{Research Article}

Keywords: Old corrugated box (OCB), pre-treatment, high-pressure homogenizer, cellulose nanofiber, lignin, hemicelluloses

Posted Date: February 11th, 2021

DOI: https://doi.org/10.21203/rs.3.rs-176521/v1

License: (9) This work is licensed under a Creative Commons Attribution 4.0 International License. Read Full License 


\title{
Cellulose nanofiber, Lignin, and Hemicellulose as value-added products from recycled Old Corrugated Box (OCB)
}

\author{
Sumit S. Lal, Ajit P. Patil, Ganesh A. Phalak and Shashank T. Mhaske* \\ Department of Polymer and Surface Engineering, \\ Institute of Chemical Technology (ICT), Matunga, Mumbai, India.
}

\author{
Correspondence to: \\ *Dr. Shashank T. Mhaske \\ Department of Polymer and Surface Engineering, \\ Institute of Chemical Technology (ICT), \\ Nathalal Parekh Marg, \\ Matunga (East), \\ Mumbai- 400 019, \\ India. \\ Phone: +919930843522 \\ Email ID: stmhaske@gmail.com \\ st.mhaske@ictmumbai.edu.in \\ ORCID: 0000-0002-4424-8919
}




\begin{abstract}
Herein, preparation and modification of cellulose nanofibers (CNF) from recycled old corrugated box (OCB) raw material is reported. CNF were synthesized from cellulose microfiber obtained after the pre-treatment of alkaline, acetic acid/sodium chlorite followed by bleaching with hydrogen peroxide. Intermediate fractions during the pretreatment were collected and examined for the lignin and hemicelluloses contents using FTIR, GPC, GC-MS and HPLC methods. Both the treated and untreated OCB microfibers were analyzed using XRD, TGA, and SEM to confirm the removal of non-cellulosic contents. Resultant pre-treated microfiber was break-down into nanofibers under high-pressure using high-pressure homogenizer at $\approx 1600$ bar pressure for 30 cycles. Nanofibers were characterized by SEM which shows the average diameter of $\approx 66 \mathrm{~nm}$. XRD analysis confirms the crystalline nature and a cellulose type-I structure of the nanofiber. In addition, obtained nanofibers were chemically surface modified by $12.91 \%$ of acetyl and $72.23 \%$ of carboxyl groups by varying reaction conditions.
\end{abstract}

Keywords: Old corrugated box (OCB); pre-treatment; high-pressure homogenizer; cellulose nanofiber; lignin; hemicelluloses

\title{
Statement of novelty:
}

Utilization of recycled old corrugated box (OCB) for selectively removal of value-added products like, (1) partially purified cellulose microfibers used to prepare cellulose nanofiber $(\approx 66 \mathrm{~nm})$ using high-pressure homogenizer after 30 cycles, (2) lignin (consist fractions of guaiacol, eugenol and syringol) and (3) hemicellulose (consist fractions of xylose, glucose and arabinose). Which are obtained after the pre-treatment processes like alkali, acetic acid/sodium chlorite and peroxide. Resultant, fractions of hemicellulose and lignin can be further purified to get the pure form of products. Further, chemically modified cellulose nanofibers can be used for composite applications. Overall, described method and the obtained value-added products can be an additional economical development and waste management for the pulp and paper industries. 


\section{Introduction}

Plant-based cellulose microfibers (CMF) have the potential to be broken-down into nanofibers of upto nanometer $(>100 \mathrm{~nm})$ diameter which is much thinner than those obtained from any other sources like bacterial cellulose, electrospining, etc. It has shown great impact in various applications due to their characteristic features like high aspect ratio, high surface area, and high tensile strength, light weight and low thermal expansion [1]. Taking this in consideration many researchers extensively studied the extraction of cellulose nanofiber from various plants (cotton, wood, flax, hemp, etc.), marine animal (tunicate) and bacteria sources to obtain products of high commercial importance [2].

In addition to that, available resources like agricultural waste, pulp and paper waste, textile industry residue and biomass are considered as a potential source of cellulose microfiber. From past several decades there has been growing interest in developing processes to extract microfibers using variety of feedstock. Pulp and paper industries are one of the major producers of scrap and recycle waste paper, exploring these waste as a raw material for various applications is essential for the sustainable environment and economical development [2]. Among various grades of waste paper, old corrugated boxes (OCB) holds $40 \%$ of the total waste paper [3]. Although, recycling of old corrugated box (OCB) is highly appreciable and routine process from environmental and economical point of view [3]. But, multiple recycling of these old currogeted box causes deterioration in fiber quality, loss of mechanical strength, shortening of fiber length, loosing valuable contents from fiber surface and decrease in swelling ability. These aspects eventually affect the property of OCB pulp and limit its reuse [4]. Processes like mechanical refining [5], chemical treatment [6] and enzyme treatment [7] are the effective alternative to improve the property of recycled OCB pulp. Amongst these, chemical treatment is most preferred methods in order to separate all the contents of OCB microfibers in a controlled way [8]. It is well known that the OCB microfibers are mainly composed of cellulose, lignin, hemicelluloses and other impurities. Chemical treatment is a method of choice for the selectively removal of lignin, hemicelluloses and cellulose [9].

Keeping in view the limited information about recycled OCB microfibers as a potential source of nanofiber and noncellulosic (lignin and hemicelluloses) content. Considering this as an opportunity, from this work an attempt has been made to prepare nanofibers out of it in a very précised way and, tried to identify the value added compounds like lignin and hemicelluloses during the process. OCB microfiber structure is a lignin-carbohydrate complex (LCC) network of lignin, hemicelluloses and cellulose, in which cellulose fibrils are linked with hemicelluloses and 
embedded lignin as a 'glue or natural binder' [10]. Owing to this barrier, core cellulose is inaccessible for chemical and enzymatic treatments. So to overcome this problem pre-treatment is needed to eliminate the surface bound lignin and hemicelluloses [11]. Conventionally, pre-treatment method consists of sulphur and chloride based chemical for pulping and bleaching process. Unfortunately, these processes have an adverse impact on environment and biological systems, so the process has been strictly prohibited under environmental acts [12]. Recently, processes reported for the removal of non-cellulosic contents involves the treatment of dilute acid, alkali, steam explosion, AFEX, Klason, Organosolve (Alcell process) and Kraft process, etc. [13]. Thus, use of acetic acid in combination with defined amount of sodium chlorite $\left(\mathrm{NaClO}_{2}\right)$ is most favorable way for the selectively removal of lignin. Because of its high efficiency, low cost, easy to handle or dispose. The mixture of acetic acid and sodium chlorite offers the formation of oxide radical at $\mathrm{pH} 4-4.5$, these radicals further accomplished with a substitution reaction by attacking on ethylene and carbonyl carbons present in lignin to offer acetylation of lignins [13]. In addition, hydrogen-peroxide under alkali condition forms hydroxyl $\left(\mathrm{HO}^{-}\right)$and superoxide anion $\left(\mathrm{O}_{2}^{-}\right)$radicals which disrupts the intermolecular bond between remaining lignin and hemicelluloses from cellulose. Free radicals, effectively depolymerizes the lignin and hemicelluloses by cleavage of carbon-carbon linkages or carbohydrate degradation, releasing lignin-carbohydrate fractions, ensuring cellulose free of any lignin and hemicelluloses [14].

Pre-treated OCB microfiber is a cheap; having low environmental impact, renewable and sustainable raw material for the preparation of cellulose nanofiber [15], and the preparation of nanofiber from acid hydrolysis, enzyme hydrolysis, etc., is among the most common processes [9]. Above mentioned methods are associated with several drawbacks, such as use of sulfuric acid which introduces sulfate groups on CNF after hydrolysis and degradation of cellulose is responsible for the reduction in thermal stability, thus imparting negative effect on cellulose structure. While in case of enzyme hydrolysis, traces of enzyme impurities always remain in the final product [2]. For these reasons, there is an increasing in efforts to find new methods for the synthesis of nanofiber. High pressure homogenizer is a potential and promising sustainable physical method for the synthesis of nanofiber [4]. As we know cellulose contains number of hydroxyl groups, and an accessibility of these groups impart enormous opportunities to prepare derivatives by increasing its employment and management [16]. Chemical modification of cellulose nanofiber by esterification, etherification, and intermolecular cross-linking reactions increases usefulness of these materials by slight altering its property [17]. Acetylation of nanofiber by mixing acetic anhydride and acetic acid in presence of catalyst such as sulfuric acid and phosphoric acid is most convenient method for the esterification of cellulose material 
[18]. Imparting hydrophobic entities over nanofiber surface are responsible for high industrial value of these materials and are utilized for the application in packaging, nanocomposite, hydrophobic coatings, bio-plastic, etc. [19]. Carboxylation of cellulose results carboxyl functionalized derivative of cellulose is another most widely used cellulose nanofiber, which deals with an oxidation of C6 hydroxyl groups to carboxylic acid with 2,2,6,6-tetramethyl piperidine1-oxyl (TEMPO). Additionally, cellulose nanocrystal modified with di/tri-carboxylic acid using acid-catalyst and cocatalyst malonic acid, malic acid and citric acid have also been reported in the literature [20,21].

Present work highlighted the extraction of partially purified cellulose microfibers from OCB raw material. Herein, during pre-treatment associated non-cellulosic contents was tested for lignin and hemicelluloses using various methods. Cellulose nanofibers were prepared from pretreated cellulose microfiber using high-pressure homogenizer and the characteristic features were evaluated using SEM and XRD, TGA analysis. Furthermore, at the application end chemical modification of nanofiber was carried out by acetyl and carboxyl entities. Substitution of functional groups was qualitatively and quantitatively estimated by FTIR and potentiometric titration.

\section{Materials and Methods}

Old corrugated boxes (OCB) were brought from local market, Matunga, Mumbai, India. Chemicals used in this work were analytical grade. $\mathrm{NaOH}$, Acetic acid (99.5\%, AR), sodium chlorite (AR), Citric acid monohydrate, Hydrogenperoxide $(30 \%, \mathrm{AR})$ these were purchase from SD Fine Chemicals, Mumbai, India.

\subsection{Isolation of cellulose microfiber from OCB box}

$500 \mathrm{~g}$ of OCB (based on dry weight) was torn into pieces and soaked in $4500 \mathrm{~mL}$ of distilled water for $24 \mathrm{~h}$ at room temperature before mechanical agitation. This mixture was pulped for $30 \mathrm{~min}$ at room temperature using IKA, RW20 Digital high speed stirrer at 2500-3000 rpm. This defibrillated material was dried at room temperature and placed in plastic bag until used.

\section{Alkali treatment}

Alkali treatment was conducted to $5 \mathrm{gm}$ of defibrillated material in $1 \mathrm{~L}$ glass reactor with $5 \%(\mathrm{w} / \mathrm{v}) \mathrm{NaOH}$ under stirring at $80{ }^{\circ} \mathrm{C}$ for $3 \mathrm{~h}$. After the treatment, fibers were vacuum filtrated, and three time washed with distilled water until the dark color totally removed and the $\mathrm{pH}$ reached to neutral.

\section{Acid treatment}

Acid treatment was carried out using different concentration of acetic acid (10, $20 \& 30 \% \mathrm{v} / \mathrm{v})$ followed by keeping the concentration of $1 \mathrm{M} \mathrm{NaClO}_{2}$ constant for $3 \mathrm{~h}$ at $80{ }^{\circ} \mathrm{C}$, throughout the process $\mathrm{pH}$ was maintain to 4 . Whereas, 
after the treatment, material was vacuum filtrated and washed with distilled water; whereas, the fraction was collected for the further analysis [22].

\section{Bleaching}

Bleaching process was performed with $\mathrm{H}_{2} \mathrm{O}_{2}(0.5,2$ and $5 \% \mathrm{v} / \mathrm{v})$ in $1 \mathrm{~L}$ glass reactor under alkali condition at pH 11 by continuously stirring at $80{ }^{\circ} \mathrm{C}$ for $3 \mathrm{~h}$. After the process, bleached material was vacuum filtrated and washed with distilled water; whereas, the fraction was collected for analysis. Finally, the obtained pure-cellulosic fibers were stored and utilized for further purpose.

\subsection{Characterization of non-cellulosic content: Lignin and hemicelluloses}

\section{Molecular weight distribution}

Molecular weight analysis of the non-cellulosic content (i.e. of lignin and hemicelluloses) in each fractions obtained after acid and bleach treatment were studied by gel permission chromatography- size exclusion chromatography (GPC-SEC), 1200 Infinity series equipped with PL aquagel-OH MIXED-H $8 \mu \mathrm{m}$ column and the effluent was monitored with refractive index detector, supplied by Agilent, USA. The testing temperature was $30{ }^{\circ} \mathrm{C}$, and the injection volume was $100 \mu$. The column was calibrated with polyethylene glycol (PEG) standards. The phosphate buffer $(\mathrm{pH}=7.2)$ flow was $1 \mathrm{~mL} / \mathrm{min}$, and the samples were dissolved in $0.1 \mathrm{M} \mathrm{NaCl}$ and stored overnight at room temperature.

\section{GC-MS analysis}

Lignin content in the fractions obtained after acetic acid (10\%, 20\% and 30\%) and sodium hypochlorite treatment were determined using GC-MS. The detail composition in the fraction was analysis by GC-MS, equipped with column TG5MS (Thermo Scientific Trace 1300). The identification of the lignin content in the fractions was confirmed based on the retention times of the standard samples recorded in NIST library

\section{Klason lignin content}

Acid-insoluble (i.e., Klason) lignin in OCB raw is determined by Klason lignin method gravimetrically (TAPPI-222 om-06). In this method, hydrolysis and solubilization of cellulose and hemicelluloses content is carried out using concentrated sulfuric acid. $1 \mathrm{gm}$ of OCB raw was placed in $100 \mathrm{ml}$ flask to which $15 \mathrm{ml}$ of $72 \%$ sulfuric acid was added. Mixture was kept on ice and keep on macerating the material for $2 \mathrm{~h}$. Now the solution is transferred to $1000 \mathrm{ml}$ flask and final hydrolysis was done with $3 \%$ sulfuric acid for $4 \mathrm{~h}$ by diluting the solution with $560 \mathrm{ml}$ of $\mathrm{D} / \mathrm{W}$ by boiling the mix for $2 \mathrm{~h}$ and maintaining the constant volume by using reflex condenser. The acid insoluble lignin starts to appeared 
and filtered using filter crucible. Filtered lignin is washed several times with hot water and dried in an oven at $105^{\circ} \mathrm{C}$ to constant weight [19].

\section{Lignin, $\%=A 100 / W$}

Where,

$A$, weight of lignin, $\mathrm{g}$

$W$, oven-dry weight of test sample, g

\section{HPLC analysis}

Hemicelluloses content in the fraction obtained after treatment with hydrogen-peroxide $(2 \%, 5 \%$ and $10 \%)$ was determined using HPLC method. The fractions obtained during the pre-treatment of OCB were analyzed for the hemicelluloses content and compared with the set of standard sugar (glucose, xylose and arabinose, $\mathrm{mg} / \mathrm{ml}$ ) contents. Selection of the standard sugar was chosen to be most closely resemble (retention time) the concentration of sugar in the test sample. HPLC analysis was performed using 1260 Agilent series equipped with Aminex 87h Biorad column, and the effluent was monitored with refractive index detector, Agilent. Testing parameters are, sample injection vol. 5 $\mu 1$, mobile phase $5 \mathrm{mmol} \mathrm{H}_{2} \mathrm{SO}_{4}$, flow rate $0.5 \mathrm{ml} / \mathrm{min}$ with run time $45 \mathrm{~min}$.

\subsection{Preparation of cellulose nanofibers (CNF) from cellulose microfiber}

\section{High-pressure homogenizer}

$0.5 \%(\mathrm{w} / \mathrm{v})$ of pre-treated OCB fibers was dispersed in $100 \mathrm{ml}$ of water and stirred for an hour. The solution was then process through a High Pressure Homogenizer (Panda Plus 1000, GEA Niro Soavi Co.) for the efficient break-down of microfiber bundles to nanofibers. Number of passes/cycles was continued until the stable suspension of nanofibers was achieved. The optimum pressure of homogenizer was adjusted to 1000-1100 bars.

\subsection{Chemical modification of cellulose nanofiber}

\section{Acetylation}

$25 \mathrm{ml}(2 \%)$ of OCB-CNF was dispersed in $20 \mathrm{ml}$ acetic acid solution by continuous stirring. A mixture of $25 \mathrm{ml}$ toluene and $5 \mathrm{ml}, 70 \%$ of $\mathrm{H}_{2} \mathrm{SO}_{4}$ was added to above solution. Then variable concentration of acetic anhydride (10, 20 \& $\left.30 \%\right)$ was subsequently added to achieve the acetylation of OCB-CNF. The reaction mixture was stirred at room temperature for $2 \mathrm{~h}$. And after the reaction obtained product was washed with ethanol three times. Finally the acetylated OCB-CNF was dried at $70{ }^{\circ} \mathrm{C}$ for $6 \mathrm{~h}$. 
The percent acetylation was determined by the titration of acetylated OCB-CNF with $\mathrm{HCl}$ solution, this method is adapted from the standardized method used for acetyl content in acetylated cellulose (ASTM D871-96) (Tabuchi, Watanabe, Morinaga, \& Yoshinaga, 1998).

$$
A c \%=[(D-C) N a+(A-B) N b] \times(F / W)
$$

Where,

$A=\mathrm{NaOH}$ solution required for titration of the sample $(\mathrm{ml})$

$B=\mathrm{NaOH}$ solution required for titration of blank $(\mathrm{ml})$

$N_{b}=$ Normality of the $\mathrm{NaOH}$ solution

$\mathrm{C}=\mathrm{HCl}$ required for titration of the sample $(\mathrm{ml})$

$\mathrm{D}=\mathrm{HCl}$ required for titration of blank $(\mathrm{ml})$

$\mathrm{N}_{a}=$ Normality of $\mathrm{HCl}$ solution

$F=4.305$ for acetyl

$W=$ weight of sample $(\mathrm{gm})$

\section{Carboxylation}

$25 \mathrm{ml}(2 \%)$ of OCB-CNF was dispersed in $100 \mathrm{ml} \mathrm{D} / \mathrm{I}$ water, sonicated for $10 \mathrm{~min}$ at $20 \mathrm{kHz}$ and continuous stirring. Further, it is mixed with citric acid monohydrate based on mole ratio of hydroxyl group of cellulose nanofiber, with varying molar concentration denoted as $0.6 \mathrm{M}, 0.8 \mathrm{M}$ and $1 \mathrm{M}$. Reaction mixture was heated to $150-160{ }^{\circ} \mathrm{C}$ for $2 \mathrm{~h}$ by constant stirring. After completion of reaction, unreacted citric acid was removed by three time wash with D/I water by centrifugation. Obtained sample were dried in an oven at $60{ }^{\circ} \mathrm{C}$.

The percent carboxylation was determined by the titration of carboxylated OCB-CNF using conductometric titration method as described by United State Pharmacopeia (USP, 1995) with some modification [24]

$$
\text { Carboxyl content }(\%)=\frac{N \times V \times M W(C O O H)}{\text { Wt. of the sample }(\mathrm{mg})} \times 100
$$

Where,

$N=$ normality of $\mathrm{NaOH}$,

$V=$ vol. of $\mathrm{NaOH}$

$M W=$ Molecular weight

$\mathrm{COOH}=$ carboxyl group

\subsection{Instrumentation:}

\section{FTIR}

FT-IR spectra were recorded on ALPHA ATR-FTIR spectrophotometer, Bruker, Germany. Parameters with scan speed $4 \mathrm{~cm}^{-1}$, ZnSe ATR crystal, scan range $4000 \mathrm{~cm}^{-1}$ to $400 \mathrm{~cm}^{-1}$. Samples were prepared by mixing with IR-grade potassium bromide and a pellet was formed using pelletizer. Pellets were placed in as assembly and test was carried out. Spectrum analysis was performed using the opus software (Version 7.2). 


\section{Color measurement}

Color was determined using Croma Meter. Untreated and treated OCB fiber samples were placed on the surface of a white standard plate and color parameter $\mathrm{L}^{*}, \mathrm{a}^{*}, \mathrm{~b}^{*}$ were measured using the CIELAB value. Three replicate tests were conducted for each sample. From the data percent reflectance, color difference $(\Delta \mathrm{E})$ and degree of whiteness $(W I)$ was calculated.

\section{XRD}

Wide angle XRD patterns were obtained using Miniflex, Rigaku, Japan with $\mathrm{CuK} \alpha$ beam having a wavelength $(\lambda)=$ $1.54 \AA$ used as the radiation source and Ni-filter. The diffractometer was operated at $30 \mathrm{KV}$ and $15 \mathrm{~mA}$. The measurements covered the scanning range of $5^{\circ}-60^{\circ}$ at a scanning speed of $3^{\circ} / \mathrm{min}$.

\section{Zeta potential}

Zeta (५) potential was analyzed using NanoPlus, Germany.

\section{SEM}

ESEM (FEI Quanta 200, ESEM FEG, and Thermo Fischer Scientific) was used to characterize the dimension of synthesized nanofiber. The samples were prepared by sputtering with platinum.

\section{TGA}

A thermal gravimetric analysis (TGA) was performed using a Pyris TGA-1, Ultra high sensitive TGA (Perkin Elmer, Germany) equipped with a nitrogen-based inert condition and an air system. All the measurements were performed in the temperature range from 40 to $650^{\circ} \mathrm{C}$ range at a heating rate $10{ }^{\circ} \mathrm{C} / \mathrm{min}$.

\section{Results \& Discussion}

OCB fiber is a promising source of cellulose nanofiber in addition to this lignin and hemicelluloses are present in significant amount which remains underutilized. Present method describes simple and industrially oriented process for the utilization of OCB raw material into a multifunctional cellulose nanofiber, and other value added products like derivatives of lignin and hemicelluloses (xylose glucose and arabinose). Four subsequent treatments were carried out on OCB raw material as given below:

\subsection{Isolation of cellulose microfiber}

The general method adopted to treat raw feedstock to extract partially purified cellulose microfibers from OCB raw are alkali, acid and bleaching treatment, as depicted in Supplementary Information-I (SI-I). [25]. Initially alkali treatment $\left(\mathrm{pH} 11,80^{\circ} \mathrm{C}\right)$ was performed to remove oil residues, impurities and disrupt the intra-molecular 
linkage between cellulose, lignin and hemicelluloses by defibrillating the OCB bundles into an individual microfiber [26].

After cellulose, lignin constitutes the higher molecular mass and it is the second highest content in OCB microfiber. Acetic acid in combination with $1 \mathrm{M} \mathrm{NaClO}$, $\mathrm{pH} 4-4.5$ at $70{ }^{\circ} \mathrm{C}$ for $3 \mathrm{~h}$, solubilizes the lignin adhered to cellulose very efficiently under condensed condition. The lignin obtained in this step having modifications in its structure which offers high solubility. In this context effect of acetic acid concentration (10, 20, and 30\%) on lignin solubility was studied. Thus, lignin content removal was initially confirmed by the FTIR analysis (Fig. 1) and the consecutive fraction (denoted as F-I-10\%, F-I-20\% and F-I-30\%) were collected and tested for lignin-derived compounds like lignin-oligomers and phenolic monomer contents by using GPC and GC-MS analysis.

In the next, bleach treatment were carried out to extract hemicelluloses, which is most closely attached molecules with lowest mass. Alkali bleach process using $\mathrm{H}_{2} \mathrm{O}_{2}\left(0.5 \%, 2 \%\right.$ \& 5\%) at $\mathrm{pH} 10-11$ at $80{ }^{\circ} \mathrm{C}$ has been tested for the maximum removal of hemicelluloses (hexoses, pentoses, etc.). The resulting material initially confirmed by FTIR and further tested by GPC and HPLC analysis.

\subsubsection{FTIR Analysis}

Fig. 1 shows the FTIR spectra of OCB fibers obtained before and after the pre-treatment processes. Broad spectral band in the region of 3500-3200 $\mathrm{cm}^{-1}$ (at approximately $3434.59 \mathrm{~cm}^{-1}$ ) corresponds to O-H stretching vibration of the hydrogen bonded hydroxyl group. The band at $1030 \mathrm{~cm}^{-1}$ relates with the $\mathrm{C}-\mathrm{O}$ stretching at $\mathrm{C}_{6}$ carbon. In addition, the band at $1162 \mathrm{~cm}^{-1}$ and $897 \mathrm{~cm}^{-1}$ corresponds to the C-O-C asymmetric stretching at the $\beta$-(1-4)-glycoside linkage $[27,28]$. These all absorption bands greatly support the presence of cellulose structure in all the OCB fibers samples.

Apart from cellulose, band appeared at around $2922.31 \mathrm{~cm}^{-1}$ is attributed to $\mathrm{C}-\mathrm{H}$ stretch vibration in aromatic methoxyl, methyl and methylene and alkyl group belongs to lignin, hemicelluloses and, cellulose [27,26]. A small peak observed at around $1740 \mathrm{~cm}^{-1}$ which is attributed to the carbonyl group $(\mathrm{C}=\mathrm{O})$ in acryl ester, aliphatic carboxylic acid groups in the p-coumaric and ferulic acids components of lignin, as well as related to uronic acid in hemicelluloses [29]. Also, a week absorption band appeared at around $1505 \mathrm{~cm}^{-1}$ may be associated with the aromatic $\mathrm{C}=\mathrm{C}$ symmetric stretching of aromatic rings (guaiacyl and syringly rings) in lignin contents [29,30]. A peak at around $1260 \mathrm{~cm}^{-1}$ represents the deformation of guaiacyl ring associated with $\mathrm{C}-\mathrm{O}$ stretch in lignin; and the axial asymmetric strain of $=\mathrm{C}-\mathrm{O}-\mathrm{C}$ commonly observed in ether, esters and phenol groups [31]. These peaks also indicate the presence 
of hemicelluloses, because it is a characteristic peak which is assign to the acyl-oxygen CO-OR stretch vibration in hemicelluloses [32].

Furthermore, after complete work up the resulting sample exhibits decrease in the intensity of these characteristic peaks is noticed, which considerably indicates the removal of lignin and hemicelluloses from OCB fibers; however when comparing this with the peaks of OCB nanofibers, there is absence of any additional peak responsible for lignin and hemicelluloses. Whereas, traces of lignin and hemicelluloses are still there, but the intensity of those peaks seems to be very week. In acetic acid (10-30\%) treatment along with $1 \mathrm{M} \mathrm{NaClO}_{2}$ at $\mathrm{pH} 4-4.5$ at $80{ }^{\circ} \mathrm{C}$, it possibly breakdowns the ester bond between the hydroxycinnamic acids and lignin or hemicelluloses, also decrease in intensity of aromatic methoxy $\left(-\mathrm{CH}_{2}\right)$ at $2854 \mathrm{~cm}^{-1}$ and ester bond at $\approx 1740 \mathrm{~cm}^{-1}$ is observed which can be seen in Fig. 1 [33]. Fractions collected at this step indicate drastic change in color as given in SI-II and it is majorly due to the presence of depolymerized and acetylated lignin detached from core cellulose fiber.

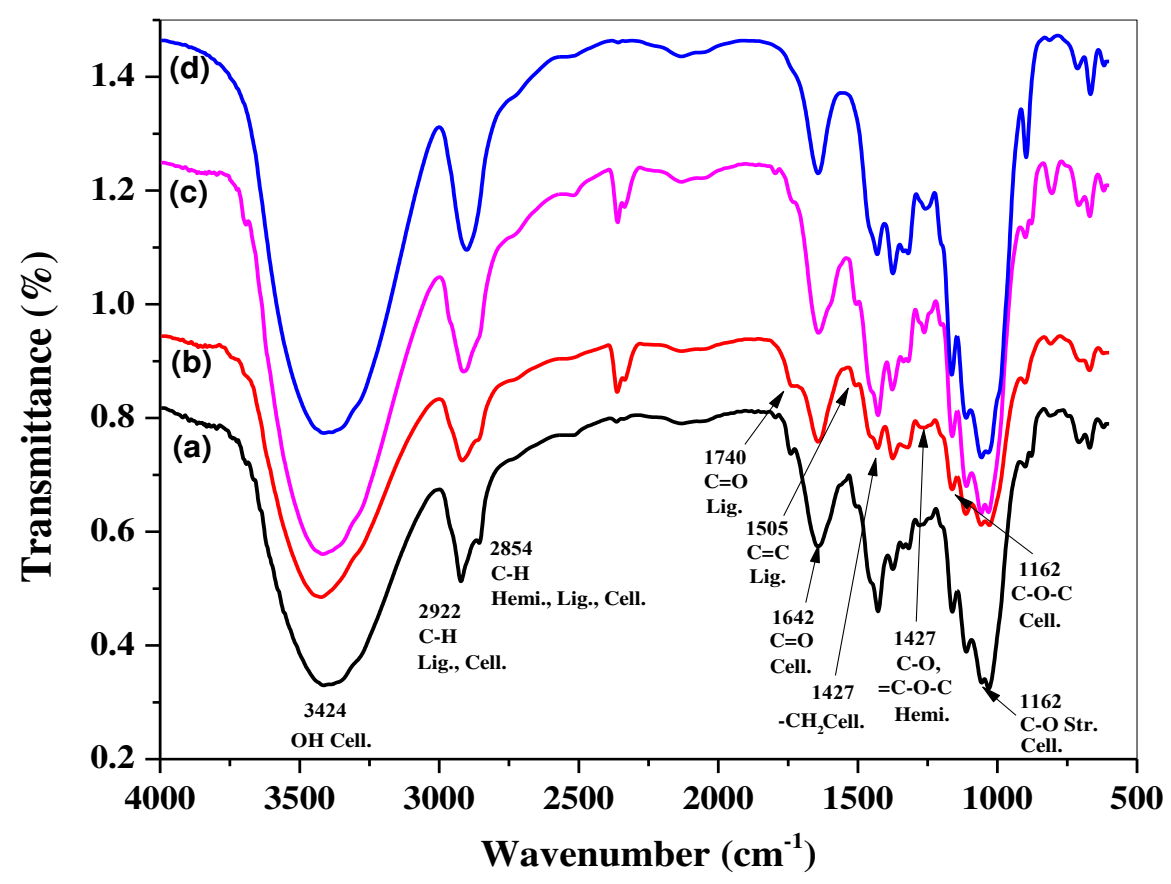

Fig 1. FTIR spectra of (a) OCB-raw, (b) OCB-acid treated, (c) OCB- bleached, and (d) OCB nanofiber

To our delight, during the bleach treatment, $\mathrm{H}_{2} \mathrm{O}_{2}(0.2,2,5 \%)$ in alkali condition enhances the process contributing peroxyacid as oxidizing agent to dissolve lignin and hemicelluloses (hexoses and pentose sugars). Hydroxide ion $\left(\mathrm{OH}^{-}\right.$ ) generated in this process acts as a strong electrophilic agent which reacts with lignin by enhancing delignification 
and brightness of fibers. Gradually, the intensity of absorption band at $1642 \mathrm{~cm}^{-1}$ seems to be decrease which is associated with $\mathrm{C}=\mathrm{O}$ str. of carboxylic anion in uronic acid in hemicelluloses [30,25]. Overall, $2 \% \mathrm{H}_{2} \mathrm{O}_{2}$ treatment seems to be optimized concentration in accordance with degree of whiteness and GPC analysis.

\subsubsection{Color measurement}

The percent reflectance of bleached treated OCB fiber was measured at wavelength from 400-700nm using UV-Visible spectrometer. Chroma Meter analyzed the samples for color space properties in terms of CIELAB color coordinates $\left(\mathrm{L}^{*}, \mathrm{a}^{*}\right.$ and $\left.\mathrm{b}^{*}\right)$. Herein, after pre-treatment percent-reflectance, color difference $(\Delta E$ or $\mathrm{DE})$ according to the CIELAB (1976) equation and whiteness index (WI) was measured and the data obtained is as shown in Fig. 2 and SI-III, three replicate tests were conducted for each sample for better precision in the results [34].

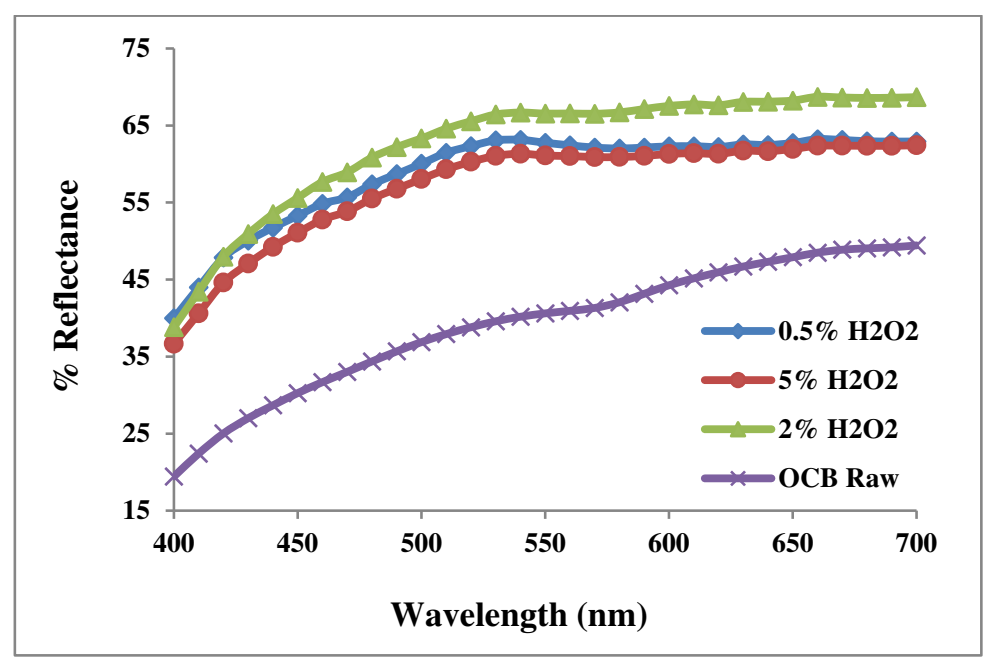

Fig 2. Comparison of UV spectra of OCB Raw with $\mathrm{H}_{2} \mathrm{O}_{2}(0.5 \%, 2 \%, \& 5 \%)$ treated OCB fibers.

Overall, variation in color is most likely due to change in chemical composition after the removal of lignin and hemicelluloses content. Increase in whiteness after $\mathrm{H}_{2} \mathrm{O}_{2}$ treatment presents close consistence with the increase in generation of hydroxyl radicals. Very interestingly, $2 \% \mathrm{H}_{2} \mathrm{O}_{2}$ in basic medium is found to be more reactive and effective for the removal of the lignin and hemicelluloses. This perhaps leads to increase the whiteness of microfibers. When comparing with OCB raw material, OCB microfibers bleached with $2 \% \mathrm{H}_{2} \mathrm{O}_{2}$ represents higher percent reflectance and color difference. This could be explain in terms of very fast decomposition of $\mathrm{H}_{2} \mathrm{O}_{2}$ under alkali condition, which results in generation of hydroxyl radicals with effective bleaching of OCB microfibers [35]. 


\subsection{Characterization of non-cellulosic content: Lignin and hemicelluloses}

Although it is very difficult to dissolve complete lignin and hemicellulose from OCB microfiber. Dilute acid and base pre-treatment at certain $\mathrm{pH}$ and heat condition could have helped in removal of hemicellulose and disrupted lignin structure. The resultant depolymarized lignin and hemicellulose was very well seen with change in colour of the collected fractions after each step (SI-II). From the mechanisctic point of view, these process primarily hydrolyzes the hemicellulose and partially solubalizes the lignin, by the cleavage of benzyl ester and glycocidic bond between lignincellulose complex (LCC) results delignification and further attached hemicellulose. Priliminary screening for the lignin was done by performing GPC analysis.

Resultant data suggested that, acetic acid with $\mathrm{NaClO}_{2}$ treatment, different molecular weight of dissolved/acetylated lignin fractions were obtained by gel permission chromatography- size exclusion chromatography (GPC-SEC) (Fig. 3). From Table. 1, peaks in fraction-I show monomodal (10 and 30\%) and slightly bimodal (20\%) curve, fraction-I 10\% and fraction-I 30\% acetic acid treatment shows single peak of low molecular weight. It may be of lignin-derived phenolic monomer product. Fraction-I 20\% acetic acid treatment presented bimodal peak which may be due to dimeric lignin-oligomer or lignin-derived monolignol linked to each other with different molecular weight distribution [36].
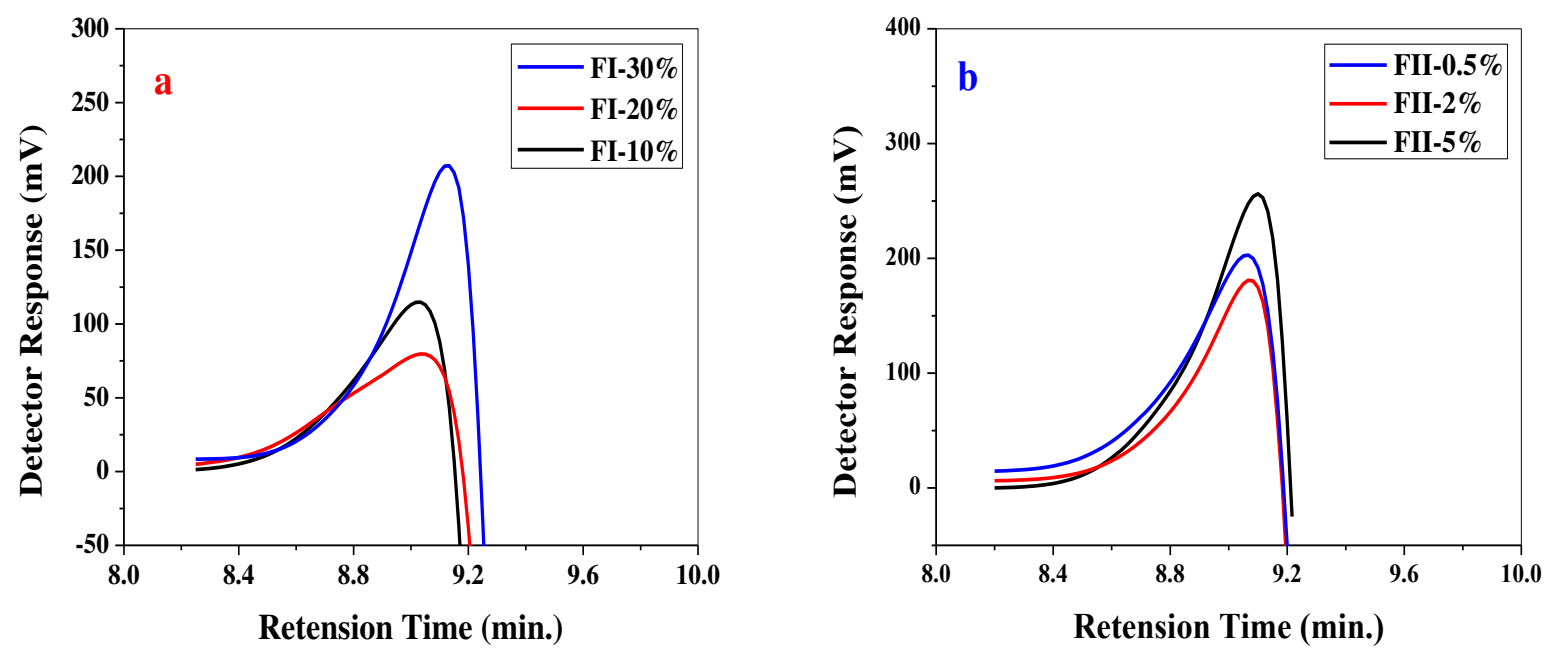

Fig 3. Apparent molecular weight distributions of

(a) lignin and (b) hemicellulose. 
The obtained results of lignin and hemicelluloses fractions are in good agreement with those reported by Sun et. al [33]. The acquire acetylated lignin fractions exhibits very low molecular weight, with very close polydispersity index, this represents higher phenolic hydroxyl content in these lignin fractions.

Table 1. $M w$ and PDI of lignin and hemicelluloses fraction

\begin{tabular}{clcc}
\hline Sr. No. & Sample name & $\boldsymbol{M w}$ & PDI \\
\hline $\mathbf{1}$ & FI-10\%-2 & 467 & 1.226 \\
$\mathbf{2}$ & FI-20\%-2 & 484 & 1.201 \\
$\mathbf{3}$ & FI-30\%-2 & 340 & 1.115 \\
$\mathbf{1}$ & FII-30-5\% & 352 & 1.139 \\
$\mathbf{2}$ & FII-30-2\% & 278 & 1.149 \\
$\mathbf{3}$ & FII-30-0.5\% & 188 & 1 \\
\hline
\end{tabular}

Mn- Number average molecular weight, Mw-Average molecular weight, PDI- Polydispercity index

On the other hand, in case of $\mathrm{H}_{2} \mathrm{O}_{2}$ treatment, most of the small amount of the remaining hemicelluloses (heterogeneous polysaccharides i.e., o-acetyle-galactoglucomannan) were dissolved or degraded into low molecular weight fractions. It may be due to lower degree of polymerization of hemicelluloses. It is essentially due to the cleavage of glycoside bonds, which is the predominant process during the bleaching treatment of OCB microfiber [37].

\subsubsection{Composition of lignin in fraction-I}

During the acid treatment cellulose structure swells, and active radicals from $\mathrm{NaClO}_{2}$ break-downs the hydrogen, ester and C-C inter-molecular linkage. It results in the complete removal of attached lignin; in addition acetic acid modifies the detached lignin molecules with acetyl groups. This allows modification in lignin structure by increasing its solubility and appeared in fraction I. This subsequent step results, 1) reduce in energy required for the breakdown of associated bonds, 2) and to extract modified lignin fractions [22]. Thus, lignin in lignin-cellulosecomplex is degraded and fragments into a mixture of relatively simple phenols as summarized in Table 2. GC-MS analysis reveals the formation of several aromatic compounds with lower molecular weight as the concentration of acetic acid is varied. As an additional result, very few peaks were distinguished and identified as a guaiacol, eugenol, syringol, and some other aromatic compounds due to oxidation and acetylation of lignin at $80{ }^{\circ} \mathrm{C}$ procession temperature. Major compounds found in the acetic acid/ $\mathrm{NaClO}_{2}$ solute are guaiacol, 4-ethylguaiacol, 4-vinylguaiacol, eugenol and syringol (SI-IV), which are mainly composed of phenylpropane units (C-6-C3) [36]. According to Daishi et. al., $\beta$-O-4 linkage of lignin could have been cleaved under acidic condition. Thus, probably these products would 
be derived from the cleavage of ether linkages in lignin. Moreover, various organic acids like linolenic acid, thiocarbamic acid, dodecanoic acid, 2-hydroxymandelic acid are also present in the fractions [38].

Table 2. Composition identified in fraction-I after acid treatment.

\begin{tabular}{|c|c|c|c|c|}
\hline RT (min) & $\mathbf{a}$ & $\mathbf{b}$ & $\mathbf{c}$ & Identified compounds \\
\hline 6.55 & - & - & - & --- \\
\hline 7.42 & - & + & - & glycerol \\
\hline 8.71 & - & - & - & --- \\
\hline 9.79 & - & - & + & 2-hydroxyhexanoic acid \\
\hline 9.80 & - & - & - & --- \\
\hline 10.03 & - & - & - & --- \\
\hline 10.05 & - & - & - & --- \\
\hline 10.07 & - & - & - & --- \\
\hline 10.26 & + & + & - & guaiacol \\
\hline 11.37 & - & - & + & 2-hydroxymandelic acid \\
\hline 12.74 & - & - & - & --- \\
\hline 13.16 & - & - & - & --- \\
\hline 13.31 & - & + & + & Dodecanoic acid \\
\hline 13.37 & - & - & - & --- \\
\hline 14.13 & - & - & - & --- \\
\hline 14.38 & - & - & + & 4-ethylphenol \\
\hline 14.56 & - & - & - & --- \\
\hline 14.77 & - & - & - & --- \\
\hline 14.97 & + & - & - & 4-ethylguaiacol \\
\hline 15.25 & - & - & - & --- \\
\hline 15.56 & - & - & - & --- \\
\hline 15.81 & - & - & - & --- \\
\hline 15.85 & - & + & - & Thiocarbamic acid \\
\hline 16.13 & - & - & - & --- \\
\hline 16.15 & - & - & - & --- - - \\
\hline 16.40 & + & + & - & 4-vinylguaiacol \\
\hline 16.46 & - & - & - & --- \\
\hline 16.58 & + & + & - & 4-vinylphenol \\
\hline 16.59 & - & - & - & --- \\
\hline 16.69 & - & - & - & --- \\
\hline 16.80 & - & - & - & --- \\
\hline 16.83 & - & - & - & --- \\
\hline 16.98 & + & - & - & eugenol \\
\hline 17.15 & - & - & - & --- \\
\hline 17.38 & + & - & - & Linolenic acid \\
\hline 17.51 & + & - & - & syringol \\
\hline
\end{tabular}

\subsubsection{Klason lignin content}

The presence of acid-insoluble (klason lignin) lignin was determined in OCB raw material. Lignin content was measured according to the TAPPI standard T249, with slight modification, obtained results are summarized in SI-V. 
Tests were carried out for almost 5 times to obtained constant value, but due to multiple washing steps, loss of final product was a major issue. However, the average amount of lignin (28.15\%) is much higher in OCB raw material (SIV).

\subsubsection{Composition of hemicelluloses in fraction-II}

Besides cellulose and lignin; hemicelluloses are considered to be another major content in OCB raw material. It has a lower strength than cellulose and can hydrolyze easily. It is a neutral polysaccharides consists of pentoses (xylose, arabinose), hexoses (mannose, glucose, and galactose), uronic acid (glucoronic, methylagalacturonic and galacturonic acid) and other sugars joined together via ester and ether linkages [39]. Ester linkages arise between the oxidized sugar and uronic acid, and the phenols and phenylpropanol functionalities in lignin. In an alkaline condition, hydrogen peroxide dissociates to form perhydroxyl anion $\left(\mathrm{HOO}^{-}\right)$, which is a strong nucleophilic agent as shown in equation (1).

$$
\mathrm{H}_{2} \mathrm{O}_{2}+\mathrm{OH}^{-} \leftrightarrow \mathrm{H}_{2} \mathrm{O}+\mathrm{HOO}^{-} \quad(\mathrm{PKa}=11.6)
$$

This perhydroxyl anion $\left(\mathrm{HOO}^{-}\right)$at $80{ }^{\circ} \mathrm{C}$ responsible for the cleavage of ester linkage and solubilizes hemicelluloses. After HPLC analysis, composition of solubilized hemicelluloses shown glucose, xylose and arabinose as main content in fraction II as summarized in Table 3. From the internal standards, arabinoses were observed in high content comparing glucose and xylose after $2 \% \mathrm{H}_{2} \mathrm{O}_{2}$ treatment. In contrast, after $5 \% \mathrm{H}_{2} \mathrm{O}_{2}$ treatment suggests sugars may have degraded due to higher peroxide content as mention in SI-VI and SI-VII. Chromatograph shows in SI-VI are of sugars and impurities (acetic acid, etc) [37].

Table 3. Composition identified in fraction-II after bleach treatment

\begin{tabular}{cccc}
\hline $\mathrm{H}_{2} \mathbf{O}_{2}(\boldsymbol{\%})$ & Glucose (g/Ltr) & Xylose (g/Ltr) & Arabinose (g/Ltr) \\
\hline 0.5 & 0.91 & --- & --- \\
2 & 0.80 & 0.23 & 1.3 \\
5 & --- & -- & 0.32 \\
\hline
\end{tabular}

\subsection{Preparation of cellulose nanofibers (CNF) from partially purified cellulose microfiber}

\subsubsection{High-pressure homogenizer}

$2 \%$ OCB pulp was form by dispersing it in $5000 \mathrm{ml}$ of $\mathrm{D} / \mathrm{I}$ water. The reaction mass was allowed for high speed stirring at $2000 \mathrm{rpm}$ for $1 \mathrm{~h}$, which offers uniformly disperse microfiber solution. This microfiber solution was passes through the high-pressure homogenizer achieving maximum pressure to obtain a uniform and stable nanofiber solution. Whereas, high-pressure homogenizer is a purely mechanical process; in which an intense energy is dissipated 
by forcing microfiber solution to pass through a narrow gap (homogenizing nozzle) at an extremely high-pressure. During the process microfiber suspension is subjected to a very high shear stress which results in break-down of microfiber $(\approx 18.72 \mu \mathrm{m}$ diameter $)$ into tiny fibrils of up to $\approx 66 \mathrm{~nm}$ ranges. From Fig. 4 (a-b) as the number of cycles is increased pressure split off microfiber into small bundles and even further increase in cycle results into tiny fibers with high aspect ratio. After 10 to 15 cycles, maximum homogeneous phase is achieved; even the zeta potential reaches to $3.52 \mathrm{mV}$. At this time point maximum pressure is implemented on microfiber to break-down it into tiny fibrils. Zetapotential indicates gradual increase in surface charges, due to exposure of hydroxyl groups.

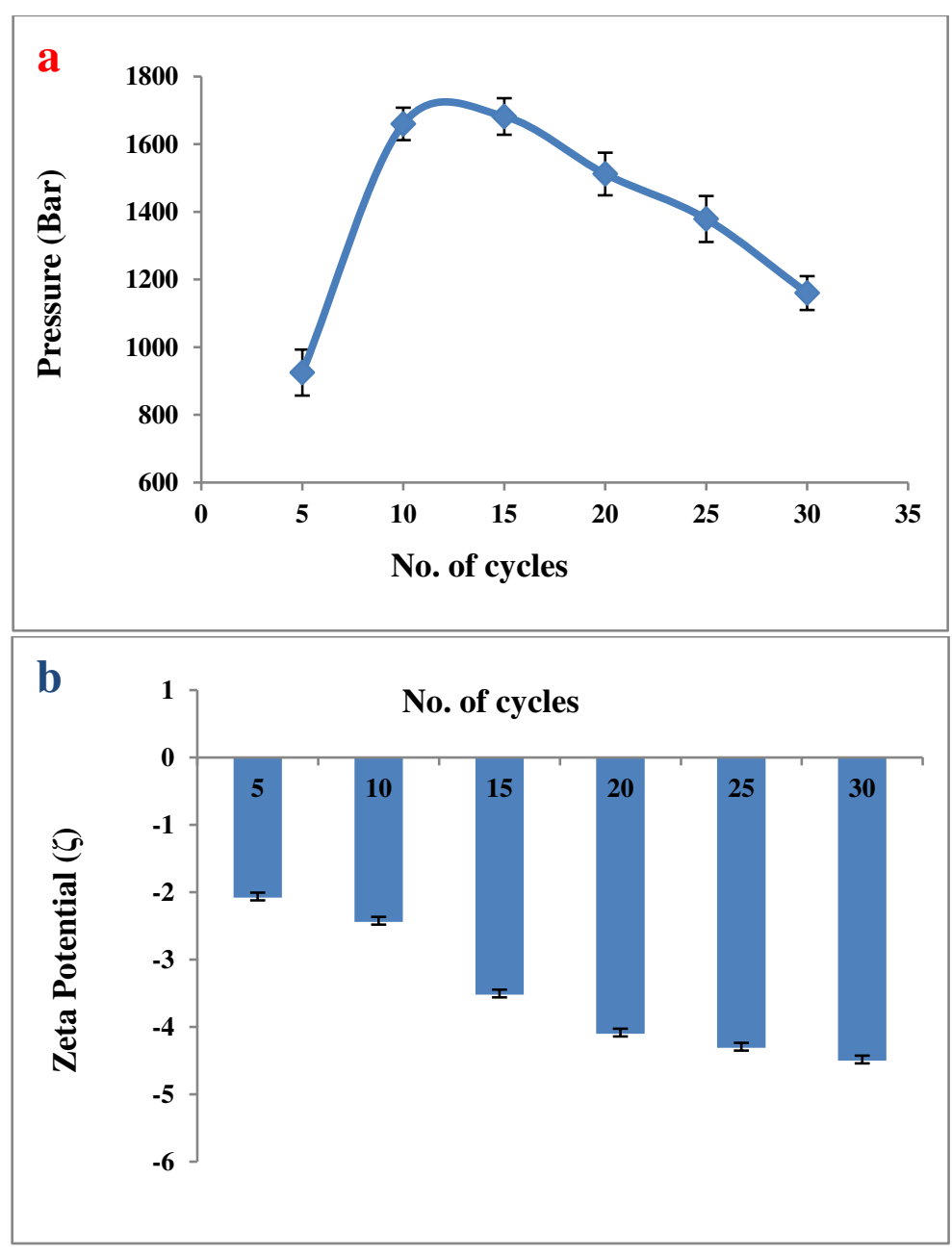

Fig 4. Pressure achieved (a) and Zeta-potential (b) of nanofiber after every 5-cycles of homogenization 
However, beyond certain limit tiny fibers starts agglomeration. Thereafter, increase in passes may damage the nanofiber structure [40]. Up to 30 cycles, zeta potential reaches to -4.50 and an average diameter of nanofiber achieved is $\approx 66 \mathrm{~nm}$.

\subsubsection{Surface morphology: Scanning Electron Microscopy}

The closure scrutiny of Fig. 5 shows surface morphology of OCB raw and OCB nanofiber. Untreated OCB raw appears as microfiber bundles of average 23- $48 \mu \mathrm{m}$ diameter, which are tightly bound with an adhesive substance 'natural binder', probably lignin and hemicelluloses. Adhesive also gives a smooth surface to microfiber [41]. However, due to recycled material some tiny fibers are oozes out of the microfiber bundle (Fig. 5 a, b). After homogenization these bulky microfiber has been broken down by releasing tiny fibers in the form of network as can be seen if Fig. 5 e, at 2000X magnification. Further, under high magnification individual tiny fibers started visible, the size of these fibers were found to be average diameter of $\approx 66.92 \mathrm{~nm}($ Fig. $5 \mathbf{f}, \mathbf{g} \boldsymbol{\&} \mathbf{~ h})$. Under homogenization very high pressure is applied on microfiber structure, it results in rupture of microfiber in to tiny fibrils after 30-cycles.
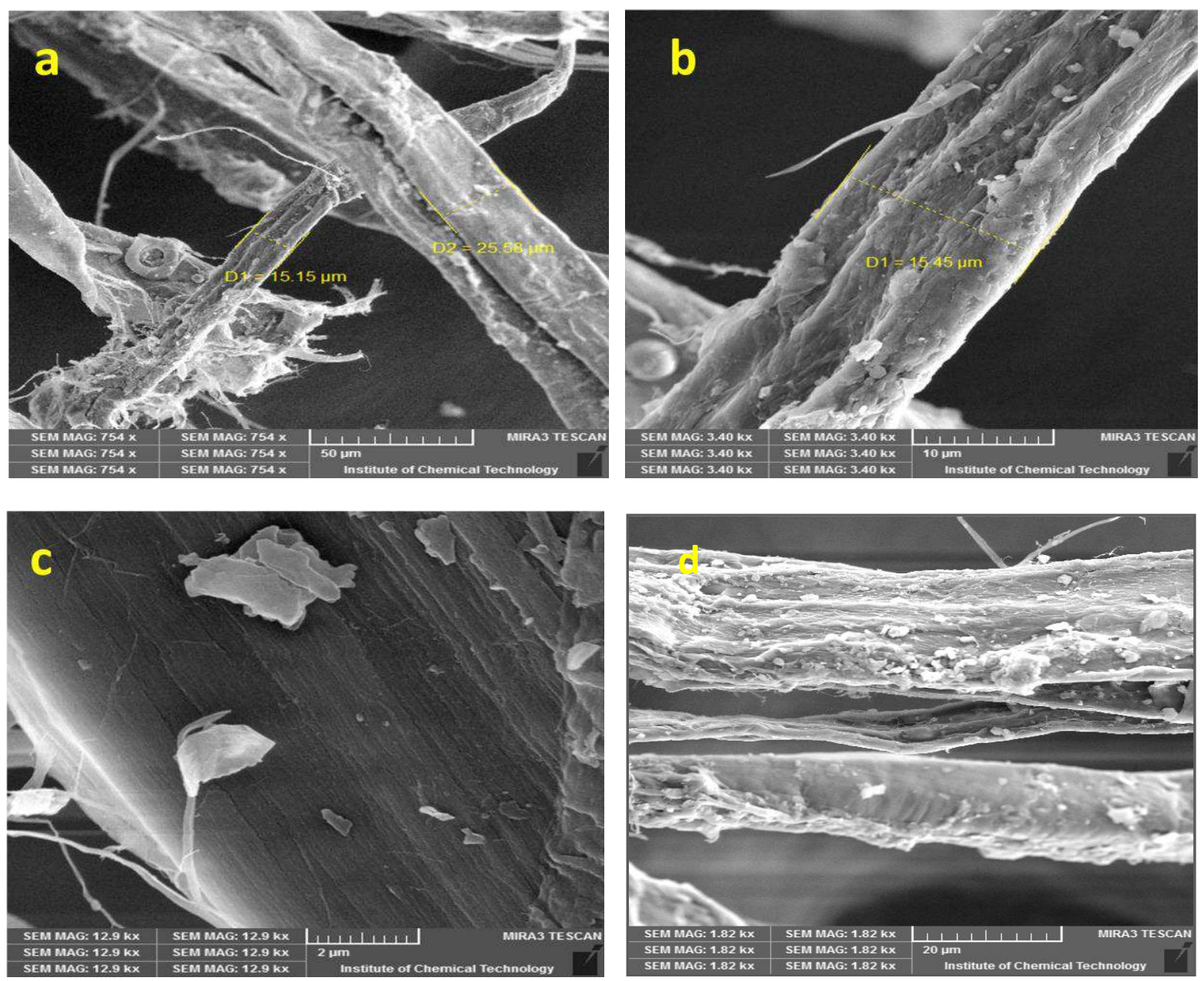

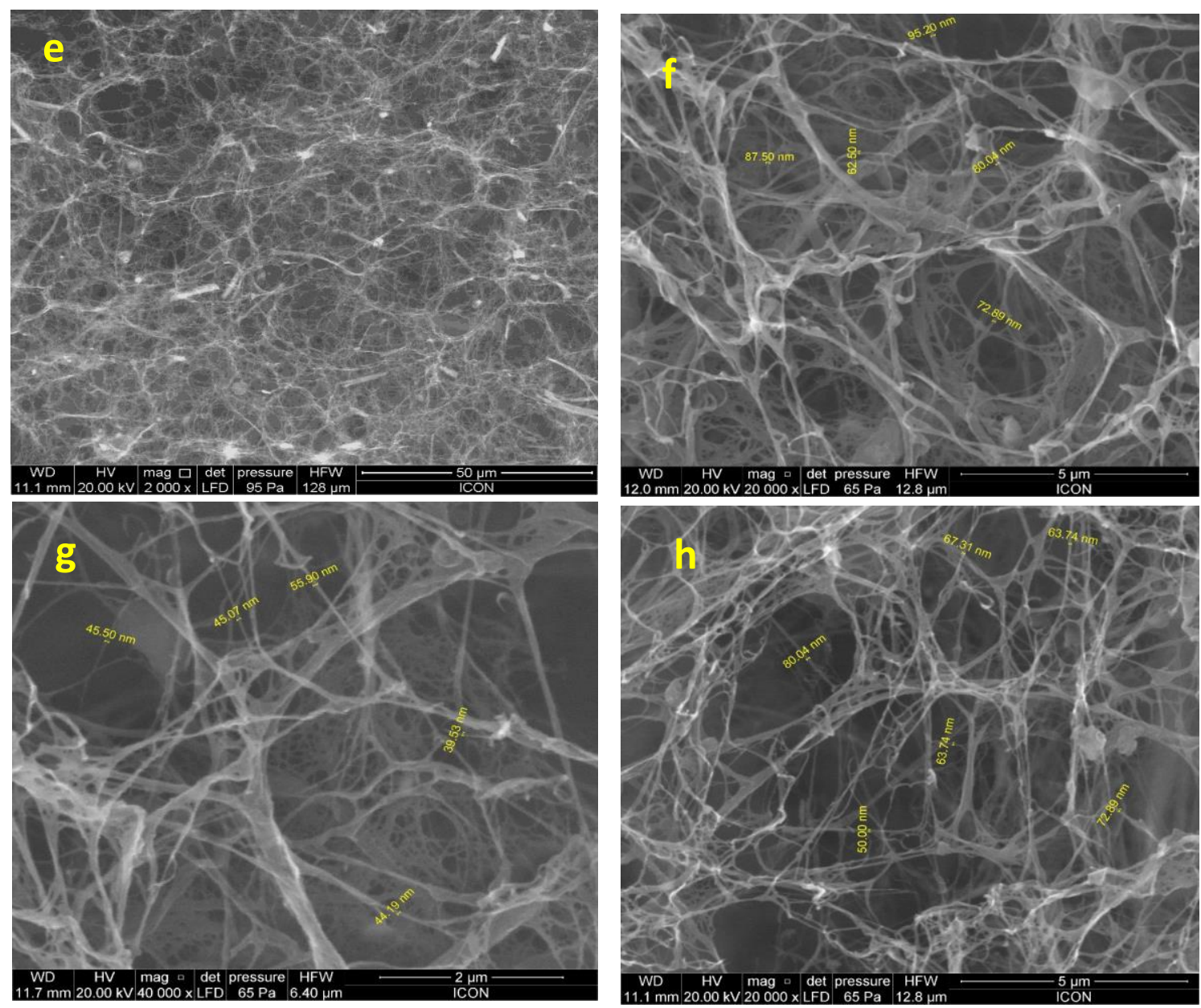

Fig 5. Surface morphology of OCB microfiber (a, b, c \& d) and nanofiber after homogenization (e, f, g \& h)

\subsubsection{X-ray diffraction analysis}

Fig. 6 Shows X-ray diffraction patterns of OCB raw, partially purified microfiber after acid, bleach treatment and nanofiber synthesized from homogenization process. The diffraction patters from nanofiber at, $2 \theta=15.28^{\circ}, 22.56^{\circ}$ and $34.2^{\circ}$ corresponds to 101,002 and 400 planes which typically represents the cellulose type I structure, with crystalline index of about $29.32 \%$ [42]. When comparing this to the OCB raw and other pre-treated microfibers, there is a noticeable difference in both diffraction pattern and crystalline index. The calculated percent crystalline data for raw, acid and bleach treated microfiber shows $27.18,28.56 \& 33 \%$ crystallinity respectively. Thus, increase in crystallinity 
from untreated to treated microfiber suggests the presence of some amorphous content and those would be the secondary molecules like lignin and hemicelluloses as 'natural binder'.

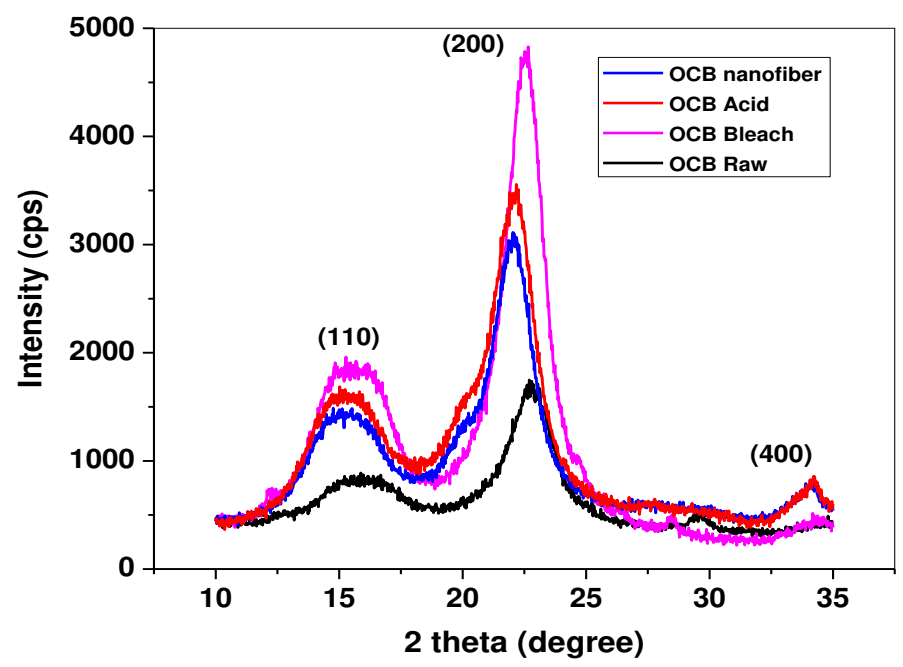

Fig 6. X-ray diffractions of untreated and treated OCB and OCB nanofiber

After successive acid and bleach treatment there is an increase in crystallinity which ultimately suggests the removal of non-cellulosic contents [43]. This is again in accordance with the FTIR characterization. In contrast, after the homogenization process crystallinity of nanofiber is reduced to $29.32 \%$ from $33 \%$. This significant decrease in crystallinity of nanofiber is probably due to the break-down of inter and intra-chain hydrogen bonding between the cellulose chain. Whereas, during the process there is displacement of characteristic peak of OCB bleached i.e. $22.6^{\circ}$ to $22.02^{\circ}$ of nanofiber propose slight disturbance in the well organized and ordered crystalline pattern during the homogenization process.

\subsubsection{Thermal analysis}

TGA and DTG curves of OCB raw, acid and bleach treated and nanofiber are demonstrated in Fig. 7 a-b respectively. Curve shows at around $100{ }^{\circ} \mathrm{C}$ i.e, initial degradation temperature $(\mathrm{Ti})$, almost all sample exhibits similar weight loss, this is may be due to the absorbed moisture. Whereas, at higher temperature i.e., maximum pyrolysis temperature (Tm) range the weight loss of all the samples was largely different from each other, which is ultimately due to the respective pre-treatments process (Table 4), a large weight loss is occurred in this stage. In this range, it is possible to comment that lignin and hemicelluloses are the only molecules which are actively degraded. Hence, the temperature required for lignin and hemicelluloses degradation is lower than that of cellulose [44]. Further, from the difference weight loss data 
i.e., $T_{d}(\%)$, it can be seen that weight loss after bleach treatment is higher than that of acid treatment. Therefore, it is assume that after acid treatment lignin molecules are degraded and after bleach treatment hemicelluloses are

Table 4. TGA of untreated, treated OCB microfibers and OCB nanofibers.

\begin{tabular}{|c|c|c|c|c|c|c|}
\hline \multirow[t]{2}{*}{$\begin{array}{l}\text { Sample } \\
\text { Name }\end{array}$} & \multirow[t]{2}{*}{$\mathrm{Ti}\left({ }^{\circ} \mathrm{C}\right)$} & \multirow[t]{2}{*}{$\operatorname{Tm}\left({ }^{\circ} \mathrm{C}\right)$} & \multicolumn{3}{|c|}{$\begin{array}{c}\text { Td }\left({ }^{\circ} \mathrm{C}\right) \text { at different weight loss } \\
\text { percentage }\end{array}$} & \multirow[t]{2}{*}{$\begin{array}{c}R W \text { at } 600 \\
{ }^{\circ} \mathrm{C}(\%)\end{array}$} \\
\hline & & & $10 \%$ & $30 \%$ & $70 \%$ & \\
\hline OCB Raw & 103.36 & 350.81 & 266.42 & 306.55 & 364.97 & 20.96 \\
\hline OCB Bleach & 63.85 & 363.19 & 288.65 & 317.99 & 367.04 & 15.45 \\
\hline OCB Acid & 64.79 & 357.75 & 297.03 & 325.67 & 363.70 & 14.26 \\
\hline OCB nanofiber & 97.74 & 346.28 & 287.82 & 315.04 & 349.14 & 10.56 \\
\hline
\end{tabular}

$T_{i}\left({ }^{\circ} \mathrm{C}\right)$ - initial decomposition temperature, $T_{m}\left({ }^{\circ} \mathrm{C}\right)$ - max. pyrolysis temperature, $T_{d}\left({ }^{\circ} \mathrm{C}\right)$ difference weight loss percentage and $R W(\%)$ remaining weight

degraded into corresponding fragments. Whereas, at higher temperature in case of acid treated microfibers degradation of lignin is accomplished very oftenly, which is probably due to their composition (aromatic ring, phenol, etc. structures) [45]. So overall, in terms of thermal stability, an OCB nanofiber seems to be the most thermally stable when compared to raw and treated OCB microfiber. Very similar thermal response was observed in DTG also for all the samples. Besides

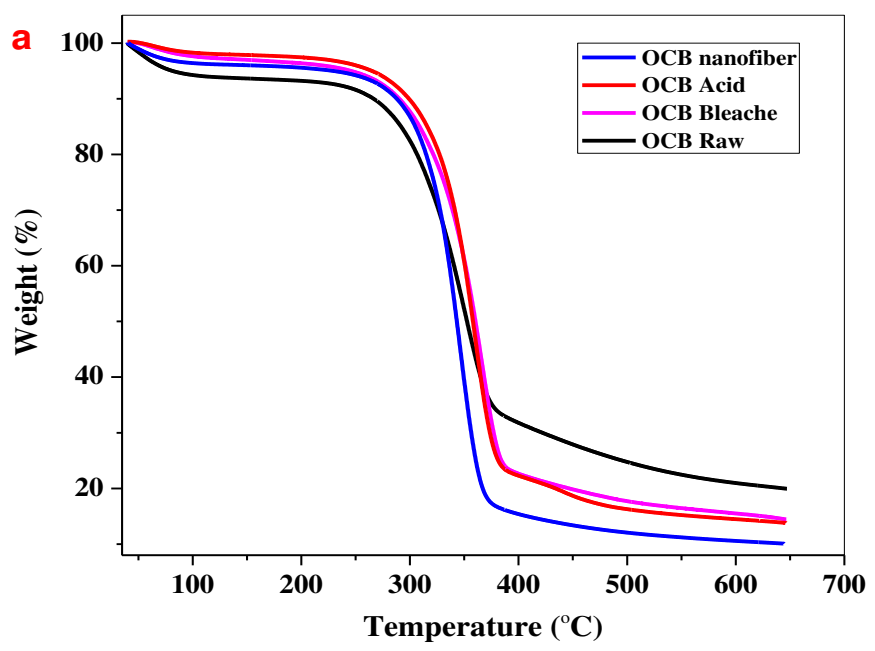




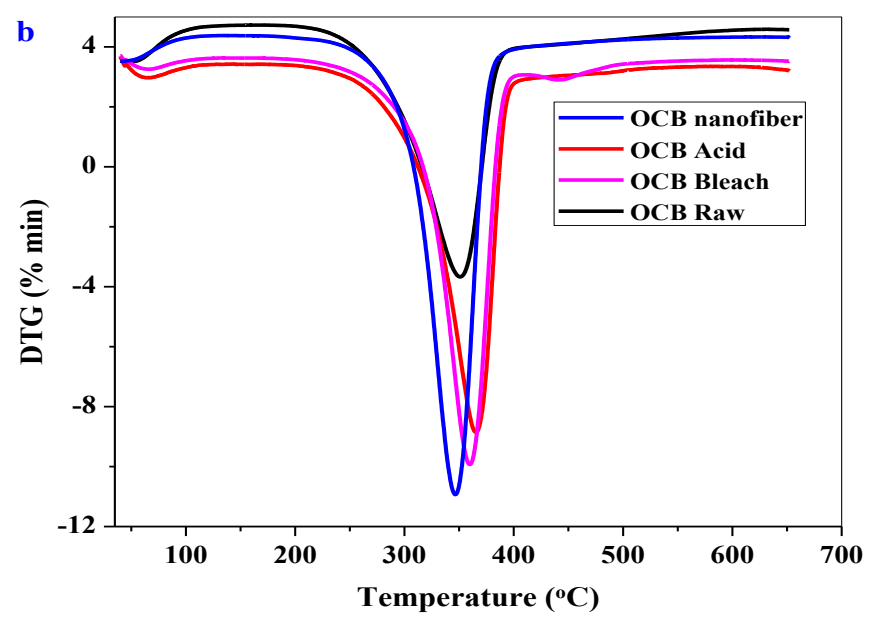

Fig 7. TGA (a) and DTG (b) OCB raw, acid, bleach and nanofiber

the remaining weight $(R W)$ of OCB raw (20.96\%) remains the highest compared to all and same for the nanofiber $(10.56 \%)$ seems to be lesser. This again results the removal of lignin and hemicelluloses content. Herein, lower the stability and least the remaining weight of nanofiber, this

is probably due to the effect of pre-treatment and homogenization process on their crystalline nature, size and adhere non-cellulosic content (lignin and hemicelluloses) [43].

\subsection{Chemical modification of cellulose nanofiber}

\subsubsection{Acetylation}

The FTIR spectra of series of acetylated nanofiber in comparison with OCB-CNF are shown in the Fig. 8-a. Increase in acetylation can be seen by increase in intensity of characteristic absorption bands like $1737 \mathrm{~cm}^{-1}, 1375 \mathrm{~cm}^{-1}$ and $1262 \mathrm{~cm}^{-1}$ which are assigned to carbonyl stretch vibration $(\mathrm{C}=\mathrm{O})$, methyl in-plane $\left(-\mathrm{CH}_{3}\right)$ and $\mathrm{C}-\mathrm{O}$ stretching $(\mathrm{C}-\mathrm{O})$, respectively [46],[47]. Whereas, characteristic vibration of the acetyl group on nanofiber were easily identified by carbonyl stretching $(\mathrm{C}=\mathrm{O})$ at $1737 \mathrm{~cm}^{-1}$. The dissociation of hydroxyl group by acetyl group on nanofiber was also confirmed by decreasing the intensity of hydroxyl group at $3385 \mathrm{~cm}^{-1}$ (Tabuchi et al., 1998).

The quantitative estimation of acetylated nanofiber was supported with the degree of acetylation and which was calculated by the titration method (Table 5). Degree of acetylation was significantly increases with increasing the percentage of acetic anhydride in acetic acid, where, the activity of acetic anhydride as reactant is enhance by $1 \mathrm{~N}$ $\mathrm{H}_{2} \mathrm{SO}_{4}$ (according to ASTMD 871-96). Herein, maximum acetylation obtained in case of $30 \%$ acetic anhydride and it was up to $8.91 \%$. However, the lowest acetylation is obtained in case of $10 \%$ acetic anhydride which was up to $6.52 \%$. 
The results suggests that the increase in acetylation can be achieved significantly in the order of $10>20>30 \%$ of acetic anhydride concentration at a given reaction temperature (Fig. 8). Similar behavior has been reported for the acetylation of bacterial cellulose by Dae-Young Kim et. al (Tabuchi et al., 1998).
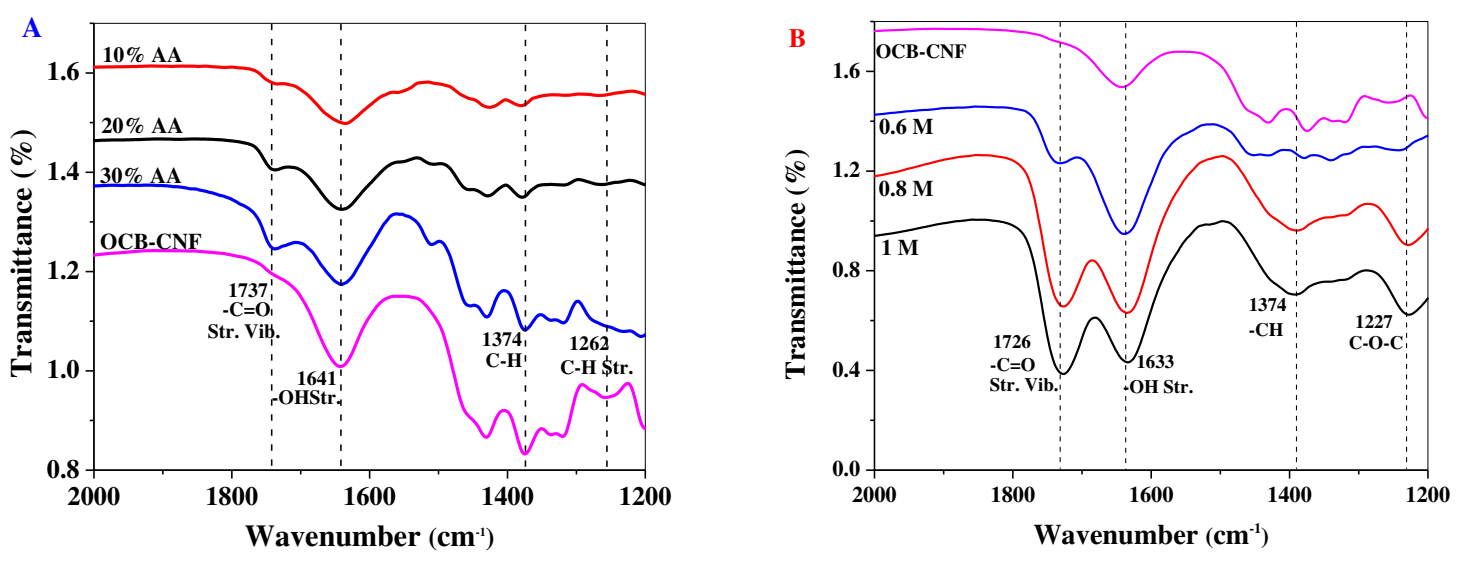

Fig 8. Represents FTIR spectra of OCB-CNF and modified OCB-CNF with (a) 10, 20, 30\% acetic anhydride and (b)

\subsubsection{Carboxylation}

$0.6,0.8$ and $1 \mathrm{M}$ citric acid.

Fig. 8-b shows FTIR spectra of carboxylated nanofiber in comparison to OCB-CNF. As, it can be seen from Fig. 1 and Fig. 8-b , OCB-CNF exhibits a characteristic absorption pattern of cellulose anhydroglucose group [48]. Whereas, a new peak appeared at $\approx 1726 \mathrm{~cm}^{-1}$ in the FTIR spectrum of modified nanofiber, which is corresponds to the ester bond when nanofiber is crosslinked with citric acid [49]. It is noted as the concentration of citric acid is increased the intensity of ester peak at $\approx 1726 \mathrm{~cm}^{-1}$ also increases significantly. Indeed, to support this, quantitative estimation of carboxyl group was carried out by potentiometric titration according to the method described by United State Pharmacopeia (USP 1995) and as reported in our previous work [48]. However, among all the concentration 1M citric acid favors $72.23 \%$ of carboxylation on nanofiber surface at $150-160{ }^{\circ} \mathrm{C}$ (Fig. 8-b) (Table 5).

Table 5. Degree of acetylation and carboxylation of cellulose nanofiber

\begin{tabular}{cccccc}
\hline & & \multicolumn{2}{c}{ Acetylation } & \multicolumn{2}{c}{ Carboxylation } \\
\hline Sr. & $\begin{array}{c}\text { OCB-CNF } \\
(\mathrm{ml})(2 \%)\end{array}$ & $\begin{array}{c}\text { Acetic anhydride } \\
(\%)\end{array}$ & $\begin{array}{c}\text { Degree of } \\
\text { acetylation }(\%)\end{array}$ & $\begin{array}{c}\text { Citric acid } \\
(\mathrm{M})\end{array}$ & $\begin{array}{c}\text { Degree of } \\
\text { carboxylation }(\%)\end{array}$ \\
\hline No. & 25 & 10 & 6.52 & 0.6 & 28.05 \\
2 & 25 & 20 & 8.58 & 0.8 & 59.31 \\
3 & 25 & 30 & 12.91 & 1 & 72.23 \\
\hline
\end{tabular}


Both the chemical modification methods, qualitatively and quantitatively results nanofiber of different physical and chemical properties. This is probably due to the two reasons, 1) mono-acetyl group on acetic acid and tri-carboxyl group on citric acid and 2) due to some adhered non-cellulosic (lignin, hemicelluloses) content which are still present on fibers and hinders the free hydroxyl group from chemical modification.

\section{Conclusion}

The present scientific scenario emphasizes over the utilization of reuse or recycled waste into value added products from the perspective of sustainable and green chemistry. This work offers quite a new approach for the conversion of recycle OCB into value added products which can be an economical opportunity to a paper and pulp industry. In this work, partially purified cellulose microfibers were successfully extracted from OCB raw material using $30 \%$ of acetic acid with $1 \mathrm{M} \mathrm{NaClO}_{2}$ and $2 \%$ of $\mathrm{H}_{2} \mathrm{O}_{2}$, which demonstrated the successful removal of lignin and hemicelluloses and obtained high quality cellulose microfibers when tested using FTIR, XRD and TGA. Intermediate fractions collected during the treatment suggested the presence of lignin derivatives (guaiacol, eugenol and syringol) and hemicelluloses (xylose, glucose and arabinose) content in a narrower molecular weight distribution, considered as a value-added material. Further, cellulose nanofibers from pre-treated OCB microfiber using high-pressure homogenizer with an average diameter of $\approx 66 \mathrm{~nm}$ were obtained. Besides, successive chemical modification of OCB nanofibers was applicable, with high percentage of acetylation (8.91\%) using 30\% acetic anhydride and carboxylation (72.23\%) using $1 \mathrm{M}$ citric acid. These chemically modified cellulose nanofibers can be used for commercialization and future application.

\section{Acknowledgement}

The author is thankful to University Grant Commission Basic scientific research (UGC BSR), New Delhi, India for the financial assistance provided in the form of fellowship in vide sanction no. F.4-1/2006 (BSR)/8-10/2007(BSR).

\section{Reference}

1. Tian, C., Yi, J., Wu, Y., Wu, Q., Qing, Y., Wang, L.: Preparation of highly charged cellulose nanofibrils using high-pressure homogenization coupled with strong acid hydrolysis pretreatments. Carbohydr Polym. 136, 485-492 (2016). https://doi.org/10.1016/j.carbpol.2015.09.055

2. Wang, H., Li, D., Zhang, R.: Preparation of ultralong cellulose nanofibers and optically transparent nanopapers derived from waste corrugated paper pulp. BioResources. 8, 1374-1384 (2013). https://doi.org/10.15376/biores.8.1.1374-1384 
3. Rahmaninia, M., Khosravani, A.: Improving the paper recycling process of old corrugated container wastes. Cellul Chem Technol. 49, 203-208 (2015)

4. Chen, Y., Wan, J., Ma, Y., Tang, B., Han, W., Ragauskas, A.J.: Modification of old corrugated container pulp with laccase and laccase-mediator system. Bioresour Technol. 110, 297-301 (2012). https://doi.org/10.1016/j.biortech.2011.12.120

5. Chen, Y., Wan, J., Ma, Y., Lv, H.: Modification of properties of old newspaper pulp with biological method. Bioresour Technol. 101, 7052-7056 (2010). https://doi.org/10.1016/j.biortech.2010.04.015

6. Cherian, B.M., Pothan, L.A., Nguyen-Chung, T., Mennig, G., Kottaisamy, M., Thomas, S.: A Novel Method for the Synthesis of Cellulose Nanofibril Whiskers from Banana Fibers and Characterization. J Agric Food Chem. 56, 5617-5627 (2008). https://doi.org/10.1021/jf8003674

7. Choi, Y., Won, J.: Improvement of papermaking properties of recycled fiber with enzyme. J Korea Tech Assoc Pulp Pap Ind. 33, 30-37 (2001)

8. Gharehkhani, S., Sadeghinezhad, E., Kazi, S.N., Yarmand, H., Badarudin, A., Safaei, M.R., Zubir, M.N.M.: Basic effects of pulp refining on fiber properties - A review. Carbohydr Polym. 115, 785-803 (2015). https://doi.org/10.1016/j.carbpol.2014.08.047

9. Wan, J., Yang, J., Ma, Y., Wang, Y.: Effects of pulp preparation and papermaking processes on the properties of OCC fibers. BioResources. 6, 1615-1630 (2011)

10. Donsí, F., Wang, Y., Li, J.I., Huang, Q.: Preparation of curcumin sub-micrometer dispersions by high-pressure homogenization. J Agric Food Chem. 58, 2848-2853 (2010). https://doi.org/10.1021/jf903968x

11. Zhao, X., Zhang, L., Liu, D.: Biomass recalcitrance. Part II: Fundamentals of different pre-treatments to increase the enzymatic digestibility of lignocellulose. Biofuels, Bioprod Biorefining. 6, 561-579 (2012). https://doi.org/10.1002/bbb.1350

12. Hamidi, N.H.: Enzymatic depolymerization of lignin by laccases, (2013)

13. Welker, C.M., Balasubramanian, V.K., Petti, C., Rai, K.M., De Bolt, S., Mendu, V.: Engineering plant biomass lignin content and composition for biofuels and bioproducts. Energies. 8, 7654-7676 (2015). https://doi.org/10.3390/en8087654

14. Mtibe, A., Linganiso, L.Z., Mathew, A.P., Oksman, K., John, M.J., Anandjiwala, R.D.: A comparative study on properties of micro and nanopapers produced from cellulose and cellulose nanofibres. Carbohydr Polym. 118, 1-8 
(2015). https://doi.org/10.1016/j.carbpol.2014.10.007

15.Chen, Y.W., Lee, H.V.: Revalorization of selected municipal solid wastes as new precursors of "green" nanocellulose via a novel one-pot isolation system: A source perspective. Int J Biol Macromol. 107, 78-92 (2018). https://doi.org/10.1016/j.ijbiomac.2017.08.143

16. Ünlü, C.H.: Carboxymethylcellulose from recycled newspaper in aqueous medium. Carbohydr Polym. 97, 159164 (2013). https://doi.org/10.1016/j.carbpol.2013.04.039

17.Zhang, Y., Nypelö, T., Salas, C., Arboleda, J., Hoeger, I.C., Rojas, O.J.: Cellulose Nanofibrils: From Strong Materials to Bioactive Surfaces. J Renew Mater. 1, 195-211 (2013). https://doi.org/10.7569/JRM.2013.634115

18. Habibi, Y.: Key advances in the chemical modification of nanocelluloses. Chem Soc Rev. 43, 1519-1542 (2014). https://doi.org/10.1039/c3cs60204d

19. Mukherjee, T., Tobin, M.J., Puskar, L., Sani, M.A., Kao, N., Gupta, R.K., Pannirselvam, M., Quazi, N., Bhattacharya, S.: Chemically imaging the interaction of acetylated nanocrystalline cellulose (NCC) with a polylactic acid (PLA) polymer matrix. Cellulose. 24, 1717-1729 (2017). https://doi.org/10.1007/s10570-017-1217$\mathrm{X}$

20. Varshney, V.K., Naithani, S.: Chemical Functionalization of Cellulose Derived from Nonconventional Sources. In: Cellulose Fibers: Bio- and Nano-Polymer Composites. pp. 43-60. Springer Berlin Heidelberg, Berlin, Heidelberg (2011)

21. Spinella, S., Maiorana, A., Qian, Q., Dawson, N.J., Hepworth, V., McCallum, S.A., Ganesh, M., Singer, K.D., Gross, R.A.: Concurrent Cellulose Hydrolysis and Esterification to Prepare a Surface-Modified Cellulose Nanocrystal Decorated with Carboxylic Acid Moieties. ACS Sustain Chem Eng. 4, 1538-1550 (2016). https://doi.org/10.1021/acssuschemeng.5b01489

22. Trifol, J., Sillard, C., Plackett, D., Szabo, P., Bras, J., Daugaard, A.E.: Chemically extracted nanocellulose from sisal fibres by a simple and industrially relevant process. Cellulose. 24, 107-118 (2017). https://doi.org/10.1007/s10570-016-1097-5

23. TABUCHI, M., WATANABE, K., MORINAGA, Y., YOSHINAGA, F.: Acetylation of Bacterial Cellulose: Preparation of Cellulose Acetate Having a High Degree of Polymerization. Biosci Biotechnol Biochem. 62, 14511454 (1998). https://doi.org/10.1271/bbb.62.1451

24. Saito, T., Isogai, A.: TEMPO-Mediated Oxidation of Native Cellulose. The Effect of Oxidation Conditions on 
Chemical and Crystal Structures of the Water-Insoluble Fractions. Biomacromolecules. 5, 1983-1989 (2004). https://doi.org/10.1021/bm0497769

25. Johar, N., Ahmad, I., Dufresne, A.: Extraction, preparation and characterization of cellulose fibres and nanocrystals from rice husk. Ind Crops Prod. 37, 93-99 (2012). https://doi.org/10.1016/j.indcrop.2011.12.016

26. Tang, Y., Shen, X., Zhang, J., Guo, D., Kong, F., Zhang, N.: Extraction of cellulose nano-crystals from old corrugated container fiber using phosphoric acid and enzymatic hydrolysis followed by sonication. Carbohydr Polym. 125, 360-366 (2015). https://doi.org/10.1016/j.carbpol.2015.02.063

27. Miao, X., Tian, F., Lin, J., Li, H., Li, X., Bian, F., Zhang, X.: Tuning the mechanical properties of cellulose nanofibrils reinforced polyvinyl alcohol composites via altering the cellulose polymorphs. RSC Adv. 6, 8335683365 (2016). https://doi.org/10.1039/C6RA14517E

28. Goh, K.Y., Ching, Y.C., Chuah, C.H., Abdullah, L.C., Liou, N.S.: Individualization of microfibrillated celluloses from oil palm empty fruit bunch: comparative studies between acid hydrolysis and ammonium persulfate oxidation. Cellulose. 23, 379-390 (2016). https://doi.org/10.1007/s10570-015-0812-y

29. Nour Eddine El Mansouri, Qiaolong Yuan, F.H.: Characterization of Alkaline Lignins for Use in PhenolFormaldehyde and Epoxy Resins. BioResources. 6, 2647-2662 (2100)

30. Mandal, A., Chakrabarty, D.: Isolation of nanocellulose from waste sugarcane bagasse (SCB) and its characterization. Carbohydr Polym. 86, 1291-1299 (2011). https://doi.org/10.1016/j.carbpol.2011.06.030

31. Silvério, H.A., Flauzino Neto, W.P., Dantas, N.O., Pasquini, D.: Extraction and characterization of cellulose nanocrystals from corncob for application as reinforcing agent in nanocomposites. Ind Crops Prod. 44, 427-436 (2013). https://doi.org/10.1016/j.indcrop.2012.10.014

32. Mohamed, M.A., Salleh, W.N.W., Jaafar, J., Asri, S.E.A.M., Ismail, A.F.: Physicochemical properties of "green" nanocrystalline cellulose isolated from recycled newspaper. RSC Adv. 5, 29842-29849 (2015). https://doi.org/10.1039/c4ra17020b

33. Sun, Fang, J.M., Goodwin, A., Lawther, J.M., Bolton, A.J.: Isolation and Characterization of Polysaccharides from Abaca Fiber. J Agric Food Chem. 46, 2817-2822 (1998). https://doi.org/10.1021/jf9710894

34. Alpay, H.R., Becerir, B., Akgun, M.: Assessing Reflectance and Color Differences of Cotton Fabrics after Abrasion. Text Res J. 75, 357-361 (2005). https://doi.org/10.1177/0040517505053807

35. Abdel-Halim, E.S.: Simple and economic bleaching process for cotton fabric. Carbohydr Polym. 88, 1233-1238 
(2012). https://doi.org/10.1016/j.carbpol.2012.01.082

36. Takada, D., Ehara, K., Saka, S.: Gas chromatographic and mass spectrometric (GC-MS) analysis of lignin-derived products from Cryptomeria japonica treated in supercritical water. J Wood Sci. 50, 253-259 (2004). https://doi.org/10.1007/s10086-003-0562-6

37. Ma, Y., Hummel, M., Määttänen, M., Särkilahti, A., Harlin, A., Sixta, H.: Upcycling of waste paper and cardboard to textiles. Green Chem. 18, 858-866 (2016). https://doi.org/10.1039/c5gc01679g

38. Del Río, J.C., Gutiérrez, A., Martínez, Á.T.: Identifying acetylated lignin units in non-wood fibers using pyrolysisgas chromatography/mass spectrometry. Rapid Commun Mass Spectrom. 18, 1181-1185 (2004). https://doi.org/10.1002/rcm.1457

39. Fan, S., Zhang, P., Li, F., Jin, S., Wang, S., Zhou, S.: A Review of Lignocellulose Change During Hydrothermal Pretreatment for Bioenergy Production. Curr Org Chem. 20, 2799-2809 (2016). https://doi.org/10.2174/1385272820666160513154113

40. Lee, S.Y., Chun, S.J., Kang, I.A., Park, J.Y.: Preparation of cellulose nanofibrils by high-pressure homogenizer and cellulose-based composite films. J Ind Eng Chem. 15, 50-55 (2009). https://doi.org/10.1016/j.jiec.2008.07.008

41. Li, J., Wei, X., Wang, Q., Chen, J., Chang, G., Kong, L., Su, J., Liu, Y.: Homogeneous isolation of nanocellulose from sugarcane bagasse by high pressure homogenization. Carbohydr Polym. 90, 1609-1613 (2012). https://doi.org/10.1016/j.carbpol.2012.07.038

42. Nasri-Nasrabadi, B., Behzad, T., Bagheri, R.: Preparation and characterization of cellulose nanofiber reinforced thermoplastic starch composites. Fibers Polym. 15, 347-354 (2014). https://doi.org/10.1007/s12221-014-0347-0

43.Zhang, P.P., Tong, D.S., Lin, C.X., Yang, H.M., Zhong, Z.K., Yu, W.H., Wang, H., Zhou, C.H.: Effects of acid treatments on bamboo cellulose nanocrystals. Asia-Pacific J Chem Eng. 9, 686-695 (2014). https://doi.org/10.1002/apj.1812

44. Asrofi, M., Abral, H., Kasim, A., Pratoto, A., Mahardika, M., Park, J.W., Kim, H.J.: Isolation of Nanocellulose from Water Hyacinth Fiber (WHF) Produced via Digester-Sonication and Its Characterization. Fibers Polym. 19, 1618-1625 (2018). https://doi.org/10.1007/s12221-018-7953-1

45. Yang, H., Yan, R., Chen, H., Lee, D.H., Zheng, C.: Characteristics of hemicellulose, cellulose and lignin pyrolysis. Fuel. 86, 1781-1788 (2007). https://doi.org/10.1016/j.fuel.2006.12.013

46.Zhou, X., Lin, X., White, K.L., Lin, S., Wu, H., Cao, S., Huang, L., Chen, L.: Effect of the degree of substitution 
on the hydrophobicity of acetylated cellulose for production of liquid marbles. Cellulose. 23, 811-821 (2016). https://doi.org/10.1007/s10570-015-0856-z

47. Tingaut, P., Zimmermann, T., Lopez-Suevos, F.: Synthesis and characterization of bionanocomposites with tunable properties from poly(lactic acid) and acetylated microfibrillated cellulose. Biomacromolecules. 11, 454-464 (2010). https://doi.org/10.1021/bm901186u

48. Lal, S.S., Mhaske, S.T.: AgBr and AgCl nanoparticle doped TEMPO-oxidized microfiber cellulose as a starting material for antimicrobial filter. Carbohydr Polym. 191, 266-279 (2018). https://doi.org/10.1016/j.carbpol.2018.03.011

49. Tang, P., Sun, G.: Generation of hydroxyl radicals and effective whitening of cotton fabrics by $\mathrm{H} 2 \mathrm{O} 2 \mathrm{under} \mathrm{UVB}$ irradiation. Carbohydr Polym. 160, 153-162 (2017). https://doi.org/10.1016/j.carbpol.2016.12.062 
Figures

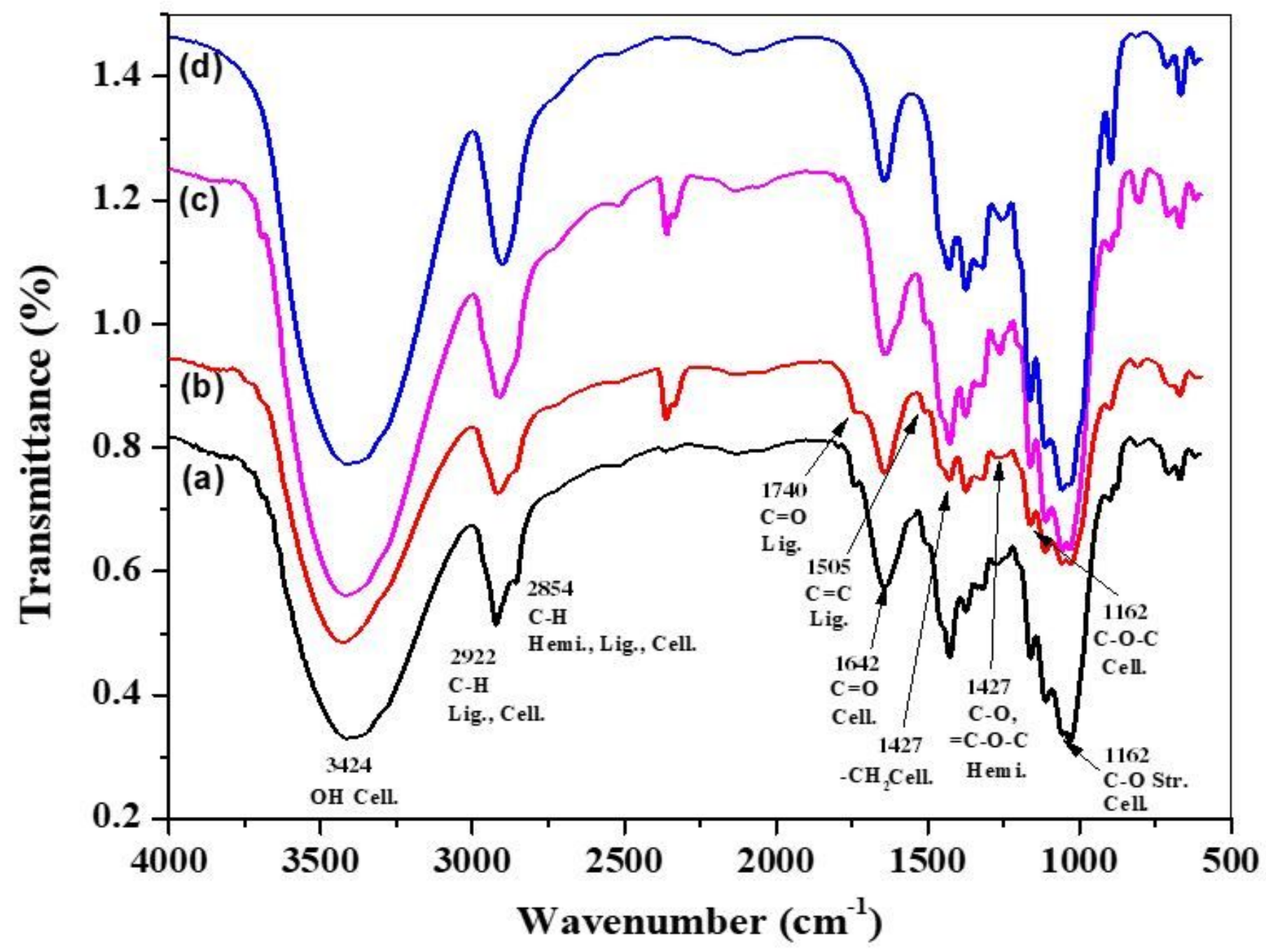

Figure 1

FTIR spectra of (a) OCB-raw, (b) OCB-acid treated, (c) OCB- bleached, and (d) OCB nanofiber 


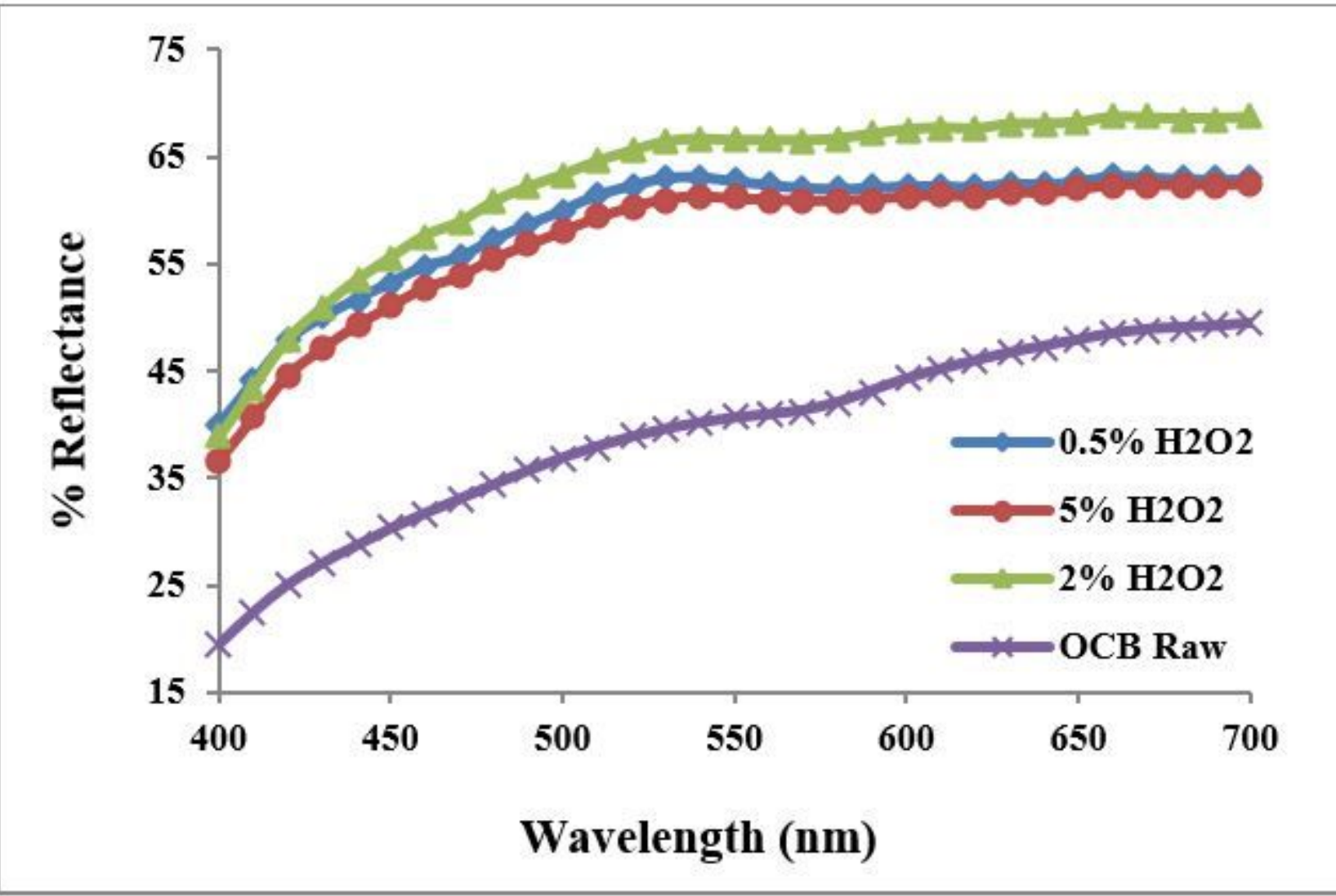

Figure 2

Comparison of UV spectra of OCB Raw with $\mathrm{H} 2 \mathrm{O} 2(0.5 \%, 2 \%, \& 5 \%)$ treated OCB fibers.
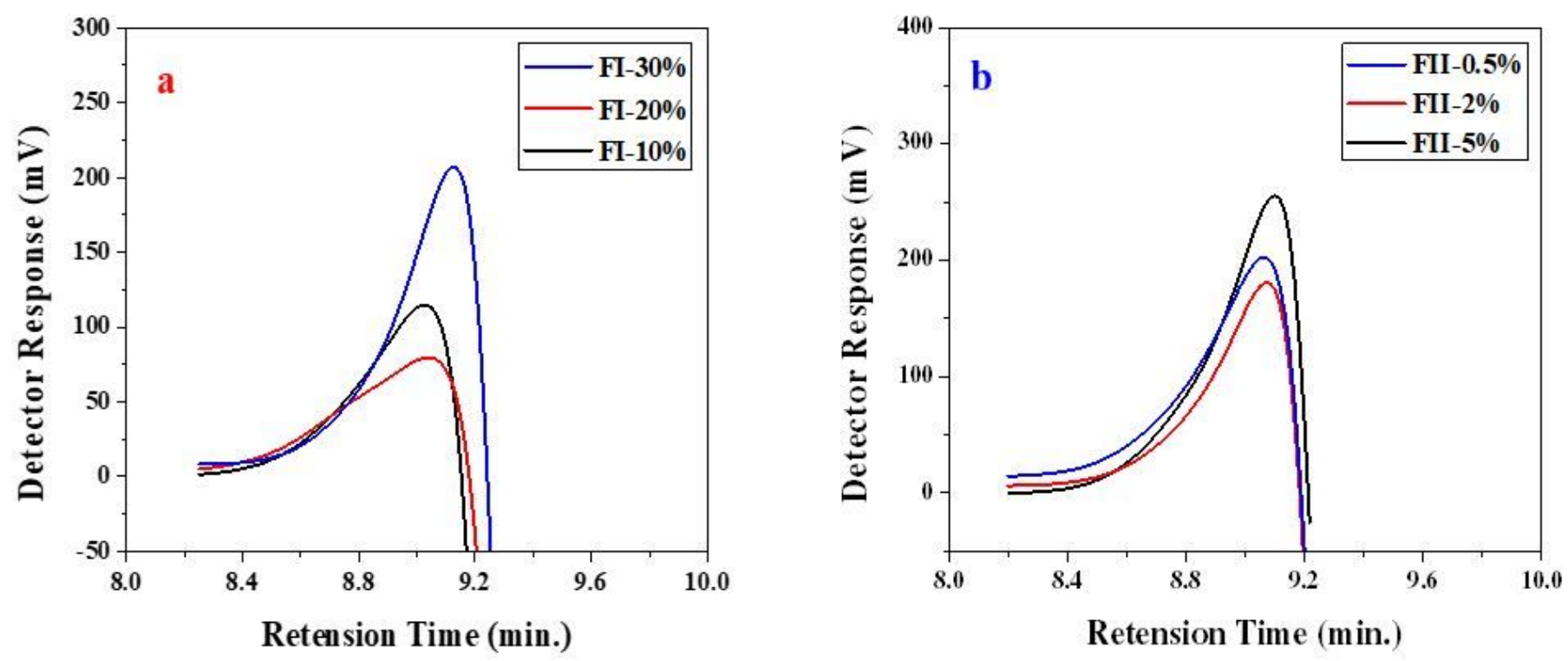

Figure 3

Apparent molecular weight distributions of (a) lignin and (b) hemicellulose. 


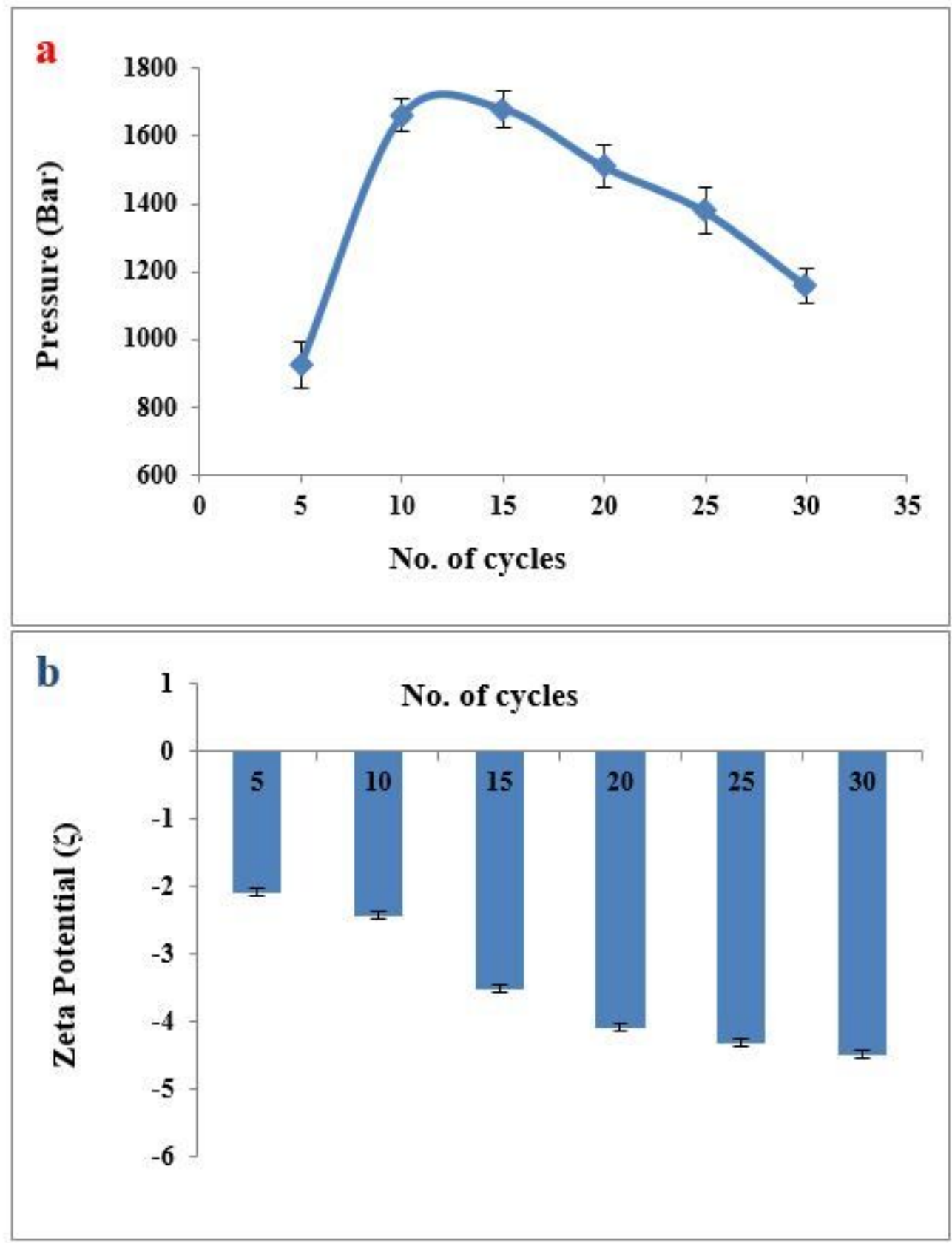

Figure 4

Pressure achieved (a) and Zeta-potential (b) of nanofiber after every 5-cycles of homogenization 

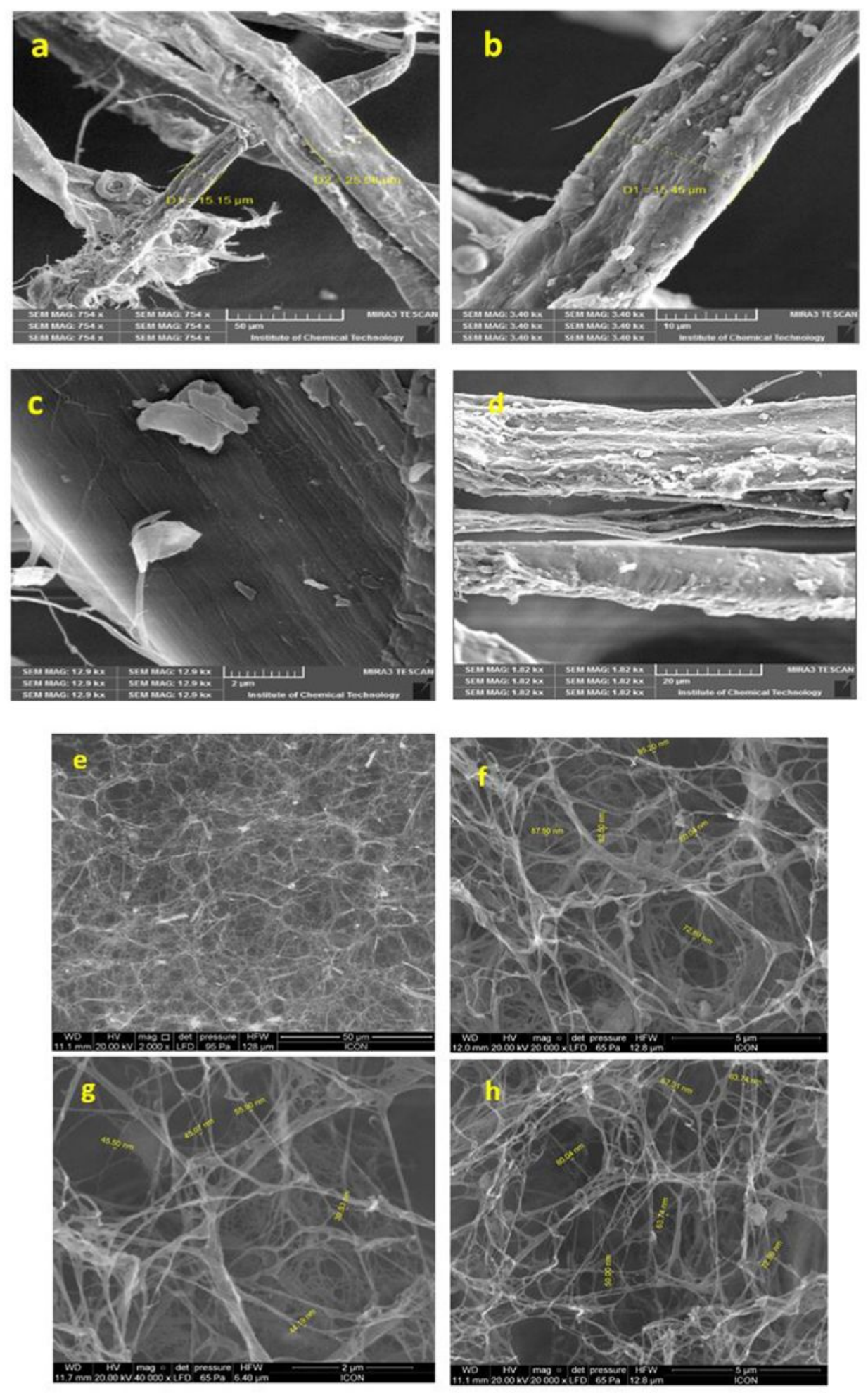

Figure 5

Surface morphology of OCB microfiber ( $a, b, c \& d)$ and nanofiber after homogenization (e, f, g \& h) 


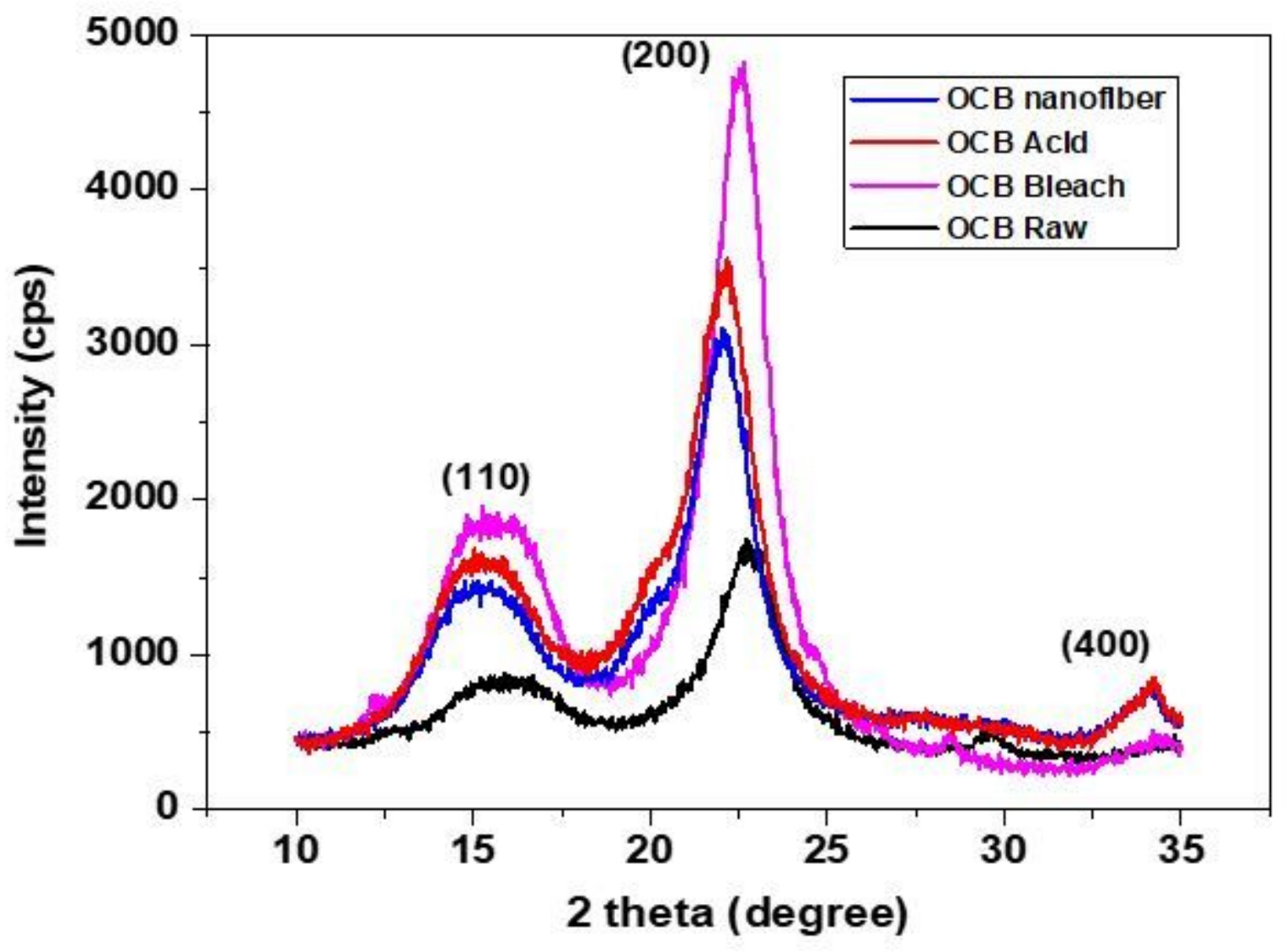

Figure 6

X-ray diffractions of untreated and treated OCB and OCB nanofiber 

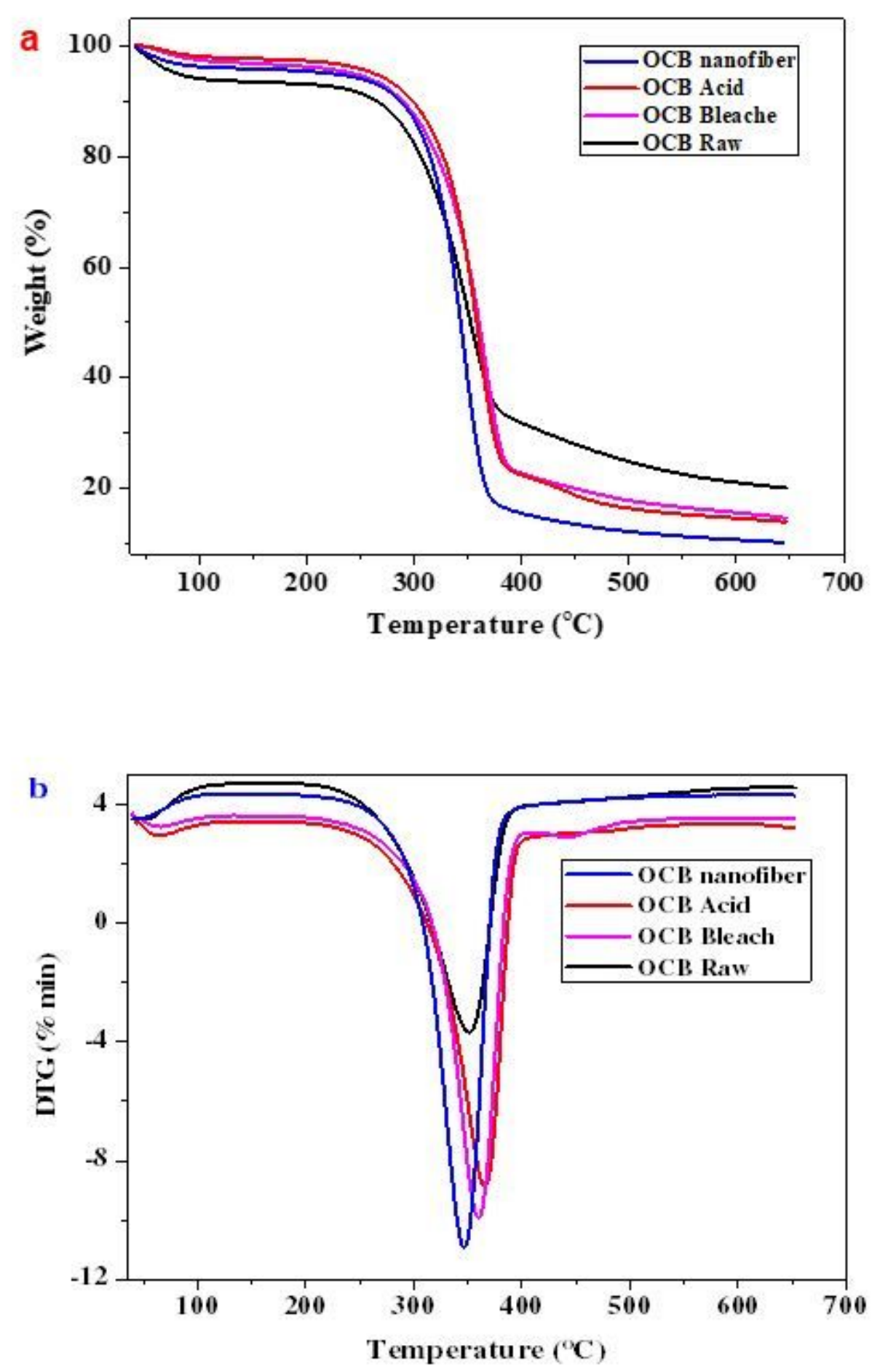

Figure 7

TGA (a) and DTG (b) OCB raw, acid, bleach and nanofiber 

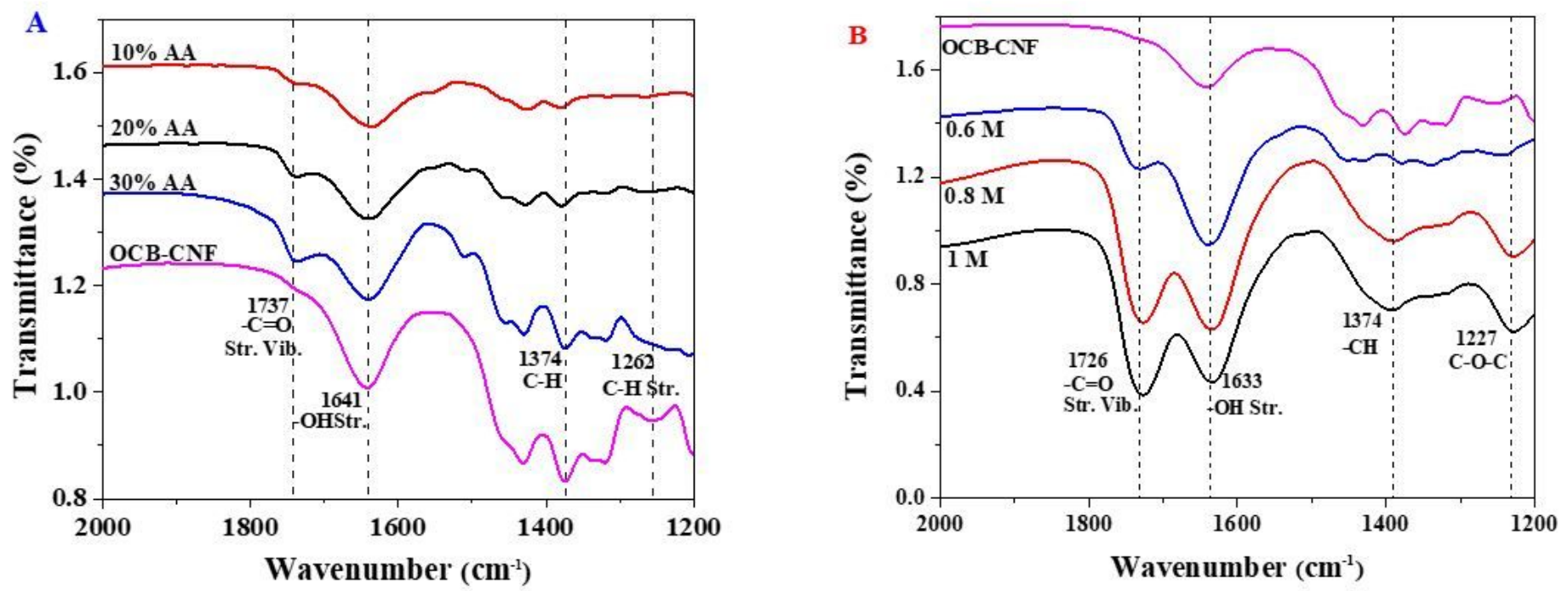

Figure 8

Represents FTIR spectra of OCB-CNF and modified OCB-CNF with (a) 10, 20, 30\% acetic anhydride and (b) $0.6,0.8$ and $1 \mathrm{M}$ citric acid.

\section{Supplementary Files}

This is a list of supplementary files associated with this preprint. Click to download.

- GraphicalAbstract.docx

- ManuscriptSI.docx 